\title{
Características generales y propiedades de las cerámicas sin metal
}

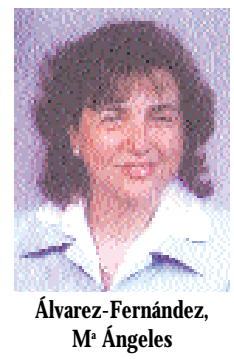

\section{General features and properties of metal- free ceramics restorations}

Álvarez- Fernández, Mạ, Ángeles* Peña-López, J osé Miguel* Conzález-Conzález, Ignacio Ramón* Oay-García, Mạ, Sonsoles**

\section{* Médico especialista en Estomatolo- gía. Profesor Asociado de Prótesis Estomatológica y Oclusión. Facultad de Odontología. Universidad de Ovie- do. \\ **Médico especialista en Estomatolo- gía. Profesor Asociado de Integrada de Adultos. Facultad de odontología. Universidad de Oviedo.}

\section{Correspondencia}

Marián Álvarez-Fernández

Servicio de Prótesis y Oclusión

Facultad de Medicina y Odontología

Catedrático J osé Serrano $\mathrm{s} / \mathrm{n}$

33006 Oviedo

E-mail: marianaf@correo.uniovi.es
Resumen: Introducción y objetivos: los actuales sistemas restauradores cerámicos sin base metálica son una realidad creciente debido a las inmejorables propiedades ópticas y estéticas que presentan gracias a su comportamiento con la luz, la capacidad para mimetizar con los dientes naturales, etc. A pesar de las ventajas indiscutibles que poseen todavía presentan algunos problemas de tipo mecánico y funcional (como la fragilidad, la fractura, la abrasión de los antagonistas, etc.) que limitan actualmente su uso generalizado como materiales restauradores. Tanto los nuevos materiales cerámicos, como los innovadores métodos de procesamiento asistidos por ordenador auguran un futuro próximo donde el uso de porcelanas libres de metal sea masivo en el quehacer diario de la profesión odontoestomatológica. Nuestro objetivo a la hora de abordar este tema es revisar los conceptos actuales sobre las porcelanas sin metal.

Material y metodología: se realiza en base a una revisión bibliográfica del tema propuesto y que se estructurará en los siguientes apartados: evolución histórica, definición del material y sinonimia, propiedades deseables o exigibles a los materiales restauradores cerámicos, ventajas e inconvenientes de ellos derivados, clasificación de las porcelanas dentales, composición de las porcelanas dentales y algunas propiedades.

Resultados y discusión: en base a los datos encontrados en la bibliografía consultada.

Palabras clave: Porcelana dental, Restauración, Tipos de porcelana, Composición, Materiales cerámicos.

Abstract: Introduction and goals: Modern restorative metal-free ceramic systems are increasingly used because of their excellent optical and aesthetic properties, due to their light transmission, their ability to mimic natural teeth, etc. Despite their advantages, some mechanical problems persist related to ceramics (such as weakness, fracture incidence, wear of opposing enamel, ...), thereby limiting their generalized use as restorative materials. Both the new ceramic materials and the CAD-CAM systems favour a massive use of all-ceramic systems in dentistry in a near future. The goal of the present article is to review the state of the art of metal-free ceramic systems. Material and methodology: Our study is carried out based on a review of the literature, structured as follows: historical evolution, definition and desirable properties of ceramic restorative materials, derived advantages and disadvantages, classification of dental ceramics, composition and properties of dental ceramics. Results and discussions: Based on the reviewed literature

Key words: Dental porcelain, Restoration, Porcelain types, Composition, Ceramics

BIBUD [1138-123X (2003)8:5; agosto-septiembre 469-592]

Álvarez-Fernández MA, Peña-López J M, González-González IR, Olay-García MS. Características generales y propiedades de las cerámicas sin metal. RCOE 2003;8(5):525-546. 


\section{Introducción}

A pesar del éxito innegable que las coronas ceramometálicas han tenido durante las últimas décadas del siglo $X X$, los esfuerzos por conseguir sistemas cerámicos libres de metal que proporcionen mayor estética no han cesado. La corona totalmente cerámica constituye un modelo estético difícil de imitar por otros medios restauradores ya que permiten una mejor transmisión de la luz a través del mis$\mathrm{mo}^{1}$. De la importancia del uso clínico de la cerámica dental basta citar que en 1990 se colocaron unos 35 millones de coronas de las cuales el $71 \%$ de las mismas tenían porcelana como uno de los componentes que las integraban, total o parcialmente ${ }^{1}$.

Sin embargo, todavía no han sido resueltos algunos de los problemas que presentan los sistemas de restauración metalcerámicos tales como el elevado coste de los metales nobles, el proceso de elaboración, el compromiso estético al disminuir la transmisión de luz a su través y la sensibilidad y alergia a determinados metales que presentan un número no despreciable de pacientes. Todo ello unido a un creciente interés por parte de la sociedad en general y de los profesionales de la odontoestomatología en particular, de obtener prótesis estéticamente perfectas ha incrementado las investigaciones encaminadas a buscar un material que respondiera a éstas expectativas (fig. 1).

En éste contexto la perfecta imitación de los tejidos duros dentales en relación a la luz incidente sólo es posible con materiales que se comporten con ella de forma similar a la que presentan los dientes naturales en cuan-
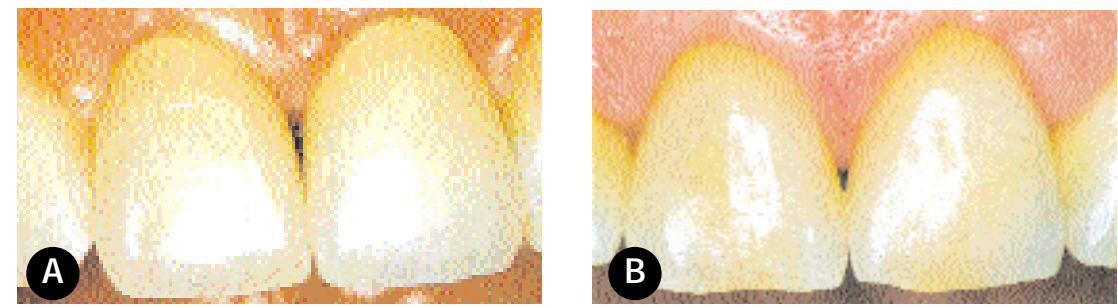

Figura 1. Restauraciones protésicas mediante coronas unitarias en incisivos centrales superiores. a/.Corona metalcerámica en 21; nótese el aspecto cervical antiestético y la tinción provocada en la mucosa por efecto del metal; b/. Corona cerámica sin metal en 11: aspecto muy estético y natural.

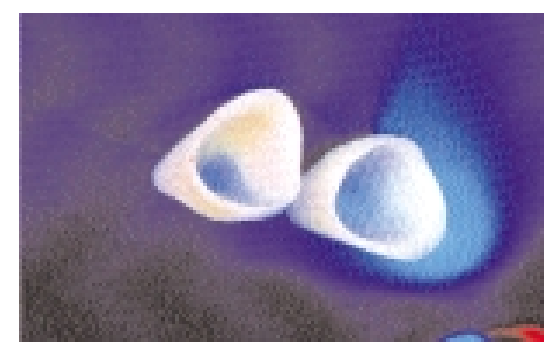

Figura 2. Translucidez que presentan las coronas de cerámica sin metal

to a translucidez, vitalidad, coloración, textura, grosor, etc.

De todos los materiales conocidos en la actualidad la porcelana dental es el material de restauración de mejor comportamiento estético de que disponemos en Odontología. Tanto es así que se considera como el material ideal por sus propiedades físicas, biológicas y ópticas que permiten mantener el color con el paso del tiempo, resistir la abrasión, además de poseer gran estabilidad en el medio oral, biocompatibilidad elevada y aspecto natural en cuanto a translucidez, brillo y fluorescencia (fig. 2).

De ahí que el gran reto para la industria y los profesionales consista en lograr prótesis exclusivamente cerámicas que mejoren o minimicen algunos de los importantes problemas que estas restauraciones aún presentan como la fragilidad y falta de resis- tencia sin perder sus excepcionales condiciones biológicas y ópticas. En este sentido la evolución histórica de los materiales cerámicos ha sido y es una dura batalla por encontrar el equilibrio entre belleza y resistencia.

La cercanía de nuevos materiales cerámicos con mejores propiedades, el vertiginoso desarrollo tecnológico de los sistemas de procesado CADCAM y los medios de adhesión y cementado actuales abren la puerta a un futuro próximo de buenos resultados tanto estéticos como mecánicos mediante coronas y puentes exclusivamente cerámicos y con elevada resistencia, hoy por hoy casi impensables de conseguir.

Nuestro objetivo al presentar ésta revisión es ofrecer una panorámica global de los sistemas cerámicos actuales sin metal intentando aproximarnos a su clasificación, composición, ventajas e inconvenientes de cada una de las porcelanas sin metal más representativas; además de efectuar un análisis comparativo y exponer finalmente las necesidades $y$ expectativas futuras de estos tipos de cerámica.

El esquema organizativo será el siguiente: breve evolución histórica, definición y sinonimia, propiedades deseables, clasificación según diver- 
sos parámetros, composición según tipo, discusión crítica, expectativas futuras y conclusiones.

\section{Evolución histórica}

La cerámica es uno de los primeros materiales producidos artificialmente por el hombre como demuestra el frecuente hallazgo de recipientes de cerámica en excavaciones y ruinas muy antiguas (23.000 años a.C) a la vez que hace patente la estabilidad química y física que éste material mantiene a través del tiempo.

La porcelana que nos ocupa es un tipo específico de cerámica, más dura, translúcida y de amplia difusión desde hace 3.000 años para diversas utilidades. Sin embargo su introducción para usos dentales se remonta a finales del siglo XVIII. Hasta esa fecha los materiales utilizados para la restitución protésica eran muy variopintos (hueso, marfil, madera, clavos, dientes de cadáveres, etc) y sufrían el mismo envejecimiento, deterioro y desgaste que los dientes naturales por la acción del medio oral.

Aunque a partir de 1717 los secretos de la fabricación de la porcelana china fueron desvelados a los europeos por los misioneros jesuitas provenientes de oriente ${ }^{3}$, las primeras aplicaciones dentales fueron debidas a la rocambolesca y mal avenida asociación de un farmacéutico parisino (Dûchateau), un cirujano dentista (Dubois de Chémant) y la fábrica de Sevrès en Francia.

A Alexis Dûchateau le surgió la idea de utilizar la porcelana como material dental al observar que los recipientes de porcelana que contenían las sustancias químicas que utilizaba en su trabajo no sufrían cambios de color ni de textura como consecuencia de los materiales que albergaban. Pero tuvo grandes problemas durante el proceso de fabricación que sólo fueron superados cuando se consuma la asociación con Dubois de Chémant que mejoró sustancialmente el método de fabricación superando en parte los problemas inicialmente encontrados.

A pesar de que los primeros dientes fabricados en porcelana presentaban grandes defectos como el grado de contracción que sufrían al cocer eran superados por la ventaja de su estética y estabilidad en el medio oral. Tanto es así que se denominaron dientes «ncorruptibles», término que ganó gran aceptación, a la par que fue sinónimo de dientes de porcelana.

Años más tarde, en 1808, un dentista italiano, G. Fonzi, publicó el primer método para producir dientes unitarios con un sistema de retención mediante pernos metálicos. No obstante la producción industrial de dientes de porcelana se inició con Claudio Ash y rápidamente EEUU que se coloca a la cabeza mundial de la producción industrial.

En éste devenir histórico las primeras coronas cerámicas puras fueron creación de Land en 1886 al idear y patentar un sistema de cocción de los dientes de porcelana sobre una hoja de platino ${ }^{4}$. La corona así constituida sería la primera corona hueca con aspiraciones estéticas en dientes unitarios ${ }^{2}$, aunque utilizadas fundamentalmente en dientes anteriores eran muy débiles y de uso clínico limitado. No obstante años antes, en 1857, E. Maynard en Washington había construido con éxito los primeros inlays cerámicos ${ }^{4}$.
Desde entonces y hasta nuestros días las investigaciones se han dirigido en su mayoría a la búsqueda de mejoras en el proceso de producción encaminado a disminuir algunos de los graves problemas que presentaban como la merma durante la cocción, aumentar la resistencia, disminuir su porosidad y en general perfeccionar la técnica de elaboración.

Así, un gran impulso fue posible con la presentación de sistemas vitrocerámicos desarrollado tras la presentación en 1930 por Carder de un método de cera perdida para la elaboración de objetos de vidrio. En éstas vitrocerámicas se produce el principio de la dispersión de la solidificación en el que se consiguen cristales mediante el proceso cerámico en la matriz de vidrio que conducen a un aumento de la solidez estructural ${ }^{4}$.

Unos años más tarde, en 1958, se produjo el mayor avance hasta ese momento en cuanto a la mejoría de la estética y la transparencia de las coronas totalmente cerámicas cuando Vines y sus colaboradores desarrollaron un sistema de procesado de las porcelanas al vacío lo que redujo considerablemente la inclusión de burbujas de aire.

Sin embargo la aportación más sobresaliente no se produjo hasta 1965 en que McLean y Hugues introdujeron una técnica para reforzar la porcelana dental con alúmina (óxido de aluminio) ${ }^{1}$ que actualmente continúa en uso. La novedad fue que colocando sobre un núcleo de óxido de aluminio porcelanas feldespáticas se mejoraban notablemente la propiedades de las coronas cerámicas puras.

Años más tarde, en 1983, se produjo un nuevo hito con la introduc- 
ción del sistema Cerestore, un sistema cerámico de alta resistencia y libre de contracción durante el procesado, que permito aumentar las indicaciones de las coronas cerámicas de más alta resistencia para los sectores posteriores ${ }^{5 *}$. En éste sistema el porcentaje de alúmina del núcleo era mayor y con un proceso de elaboración sumamente complejo, pero tenía la ventaja de que contrarrestaba la contracción durante la cocción del núcleo.

A partir de entonces el desarrollo de los sistemas cerámicos fue casi vertiginoso. Al sistema Cerestore le siguió cronológicamente el Hi-Ceram que contiene el mismo porcentaje de alúmina que Cerestore pero que simplificaba considerablemente el proceso de fabricación con lo cual el resultado final era más predecible; sin embargo la resistencia para grupos posteriores no era satisfactoria y fue sustituido por el sistema InCeram en 1996. Este sistema se basa en la realización de coronas mediante un núcleo de alúmina presinterizado con un contenido de alúmina del $70 \%$ inicialmente poroso y que posteriormente es infiltrado con vidrio (fig. 3).

Finalmente y tras otros intentos, en 1993, se dio un importante paso en el desarrollo de las cerámicas de mayor resistencia con el concepto Procera/AllCeram. Estas restauraciones constan de un núcleo de alúmina densamente sinterizada $(99,9 \%$ de alúmina) recubierta por una cerámica compatible convencional ${ }^{7 * *}$.

La introducción de estos sistemas de elevada resistencia (In Ceram y Procera/All Ceram) ${ }^{8,9}$ han posibilitado que las indicaciones se puedan
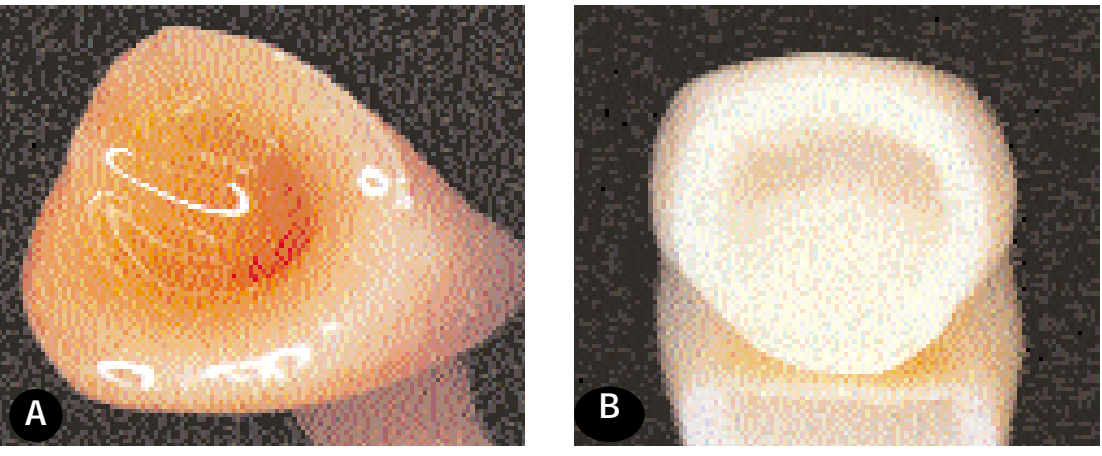

Figura 3. Corona unitaria infiltrada con vidrio. a/. Aspecto del vidrio infiltrado sobre el núcleo; b/. Vista final de la restauración.

ampliar, con reservas, a la realización de puentes de hasta tres unidades mediante la utilización de porcelana libre de metal.

En éste sentido, se están realizando numerosos estudios para comprobar si se confirman las buenas expectativas observadas inicialmente y si se cumplen a largo plazo.

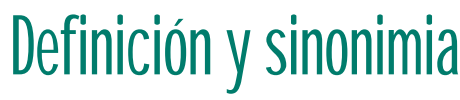

Etimológicamente, el término cerámica viene del griego keramos y significa tierra quemada, hecho de tierra, material quemado. Curiosamente se suele definir por lo que no son; no son metálicos y no son orgánicos es decir son materiales inorgánicos y no metálicos que constituyen objetos sólidos confeccionados por el hombre por horneado de materiales básicos minerales a temperaturas elevadas bien en un horno o directamente al fuego ${ }^{1,10}$ y en cuya estructura final se diferencian una fase amorfa (vidrio) y otra cristalina (cristales) ${ }^{11}$. Así, todas las cerámicas, tanto las más finas como las más toscas, están constituidas fundamentalmente por los mismos materiales siendo la dife- rencia entre unas y otras la proporción de componentes primarios o básicos y el proceso de cocción empleado. Dependiendo de los distintos compuestos que los integran, del tamaño del grano, temperatura de cocción, etc., se crea un amplio espectro de materiales cerámicos que abarcan loza, gres, porcelana y vidrio, siendo las masas cerámicas dentales tan sólo un pequeño grupo dentro del amplio espectro de las cerámicas.

En cuanto a la porcelana, ésta es una cerámica de más alta calidad, menos porosa, más dura, más rígida y con excelente aspecto y cualidades superficiales ${ }^{8}$. En ella sólo se emplean componentes de gran pureza debido a los requisitos ópticos que tiene que ofrecer. Pese a que de modo estricto, cerámica y porcelana no son exactamente lo mismo, es bien cierto que se utilizan indistintamente en la práctica odontológica dentro del amplio grupo de los materiales cerámicos. En este artículo, siguiendo la tendencia mayoritaria en la literatura específica sobre el tema que nos ocupa, se utilizarán indistintamente los términos cerámica y porcelana dental. 
Propiedades deseables en los materiales restauradores cerámicos y su relación con las ventajas e incovenientes de ellos derivados

Los materiales cerámicos dentales deben presentar una serie de propiedades que a continuación destacamos:

1. Propiedades ópticas de vitalidad, translucidez, brillo, trasparencia, color (posibilidad de incorporar pigmentos), reflexión de la luz y textura, lo que implica grandes posibilidades estéticas al mimetizar los dientes naturales ${ }^{1}$.

2. Biocompatibilidad local y general. Son los que presentan el mejor comportamiento con los tejidos vivos.

3. Durabilidad y estabilidad en el tiempo tanto en integridad coronal como en su aspecto por la gran estabilidad química en el medio bucal.

4. Compatibilidad con otros materiales y posibilidad de ser adheridas y grabadas mediante los sistemas cementantes adhesivos actuales.

5. Baja conductividad térmica con cambios dimensiónales más próximos a los tejidos dentarios naturales que otros materiales restauradores utilizados ${ }^{9}$.

6. Radiolucidez: cualidad ésta muy interesante pues permite detectar posibles cambios en la estructura dentaria tallada como caries marginales y actuar precozmente especialmente en las porcelanas de alúmina densamente sinterizadas y en las feldespáticas ${ }^{12}$.

7. Resistencia a la abrasión debido a su dureza ${ }^{13}$. Esta propiedad constituye una seria desventaja y un importante problema clínico cuando se opone a dientes naturales, pues limita las indicaciones y depende directamente de la dureza del material cerámico y de la aspereza del mismo al ocluir sobre las superficies dentarias. Actualmente se considera que la porcelana vitrificada de grano fino es menos abrasiva para el antagonista ${ }^{14}$.

8. Resistencia mecánica. Alta resistencia a la compresión, baja a la tracción y variable a la torsión, lo que las convierte en rígidas pero frágiles. Quizá sea éste el más grave inconveniente que presentan, tanto es así que los mayores esfuerzos investigadores se han dirigido a dotarlas de mayor resistencia. Al respecto, las causas más frecuentemente mencionadas como responsables de la fragilidad son la existencia de grietas en el material cerámico y la propagación de las mismas, así como la presencia de poros por una técnica descuidada durante el procesamiento, cocción, etc. La porosidad y contracción durante la cocción exigen una técnica meticulosa para mejorar los resultados. Un intento de obviar este problema fue el fundirlas sobre metal a expensas de disminuir la estética. También se mejoró la resistencia a la fractura mediante la dispersión de pequeños cristales dentro de la estructura cerámica para impedir la propagación de las grietas. La indeformabilidad que presentan ante deformaciones elásticas también contribuyen a su fragilidad si bien algunas de la actuales cerámicas presentan cierta resistencia a la flexión.
9. Procesado simple y coste razonable: la realización de coronas de porcelana no es precisamente fácil de realizar lo cual lleva aparejado un coste elevado. Sin embargo la generalización y automatización de la técnica hacen suponer que a la larga se producirá un abaratamiento de los coste de producción.

Estos tres últimos puntos constituyen los principales inconvenientes limitantes de su uso y hacia donde deben dirigirse las investigaciones para intentar solventarlos.

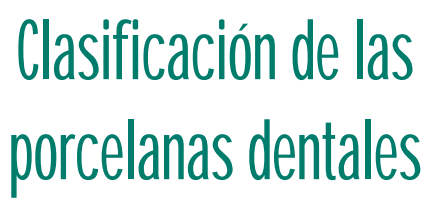

Hacer una taxonomía de las porcelanas dentales es arduo y complicado, pues los criterios de asociación son muy variados y artificiosos. En unos casos se atiende a la temperatura de procesado de la porcelana, en otros a las características estructurales o a la composición, al lugar de aplicación sobre la superficie dentaria, a la forma de elaborar o procesar las restauraciones e incluso a las indicaciones de la misma.

Entre los posibles parámetros de clasificación destacamos:

\section{Según el criterio de la tempera- tura de procesado}

La necesidad de calor para su elaboración ha conducido a que tradicionalmente se hayan clasificado en función de la temperatura a la que deben ser procesadas.

Según este criterio las porcelanas se clasifican en porcelanas de alta, media y baja fusión. Recientemente 


\begin{tabular}{|c|c|c|c|c|c|}
\hline DENOMINACIÓN & Ta & INDICACIONES & VENTAJAS & INCONVENIENTES & COMPOSICIÓN PORCENTAJE \\
\hline Alta fusión & $1300-1370 \circ \mathrm{C}$ & $\begin{array}{l}\text { Producción } \\
\text { industrial } \\
\text { de dientes }\end{array}$ & \begin{tabular}{|c|} 
\\
$>$ resistencia \\
$<$ traslucidez \\
$<$ solubilidad \\
soporta muy bien \\
modificaciones \\
repetidas \\
\end{tabular} & $\begin{array}{l}\text { Gasto } \\
\text { energético } \\
\text { elevado }\end{array}$ & \\
\hline Media fusión & $1100-1300^{\circ} \mathrm{C}$ & $\begin{array}{c}\text { Núcleo de } \\
\text { elaboración } \\
\text { de coronas } \\
\text { jacket }\end{array}$ & \begin{tabular}{|l|} 
<intervalo \\
de fusión \\
<cambio \\
dimensional \\
al enfriar \\
<porosidad \\
superficial \\
<grietas \\
superficiales
\end{tabular} & $\begin{array}{l}\text { La porcelana } \\
\text { se deforma } \\
\text { durante } \\
\text { las reparaciones } \\
\text { repetidas }\end{array}$ & \begin{tabular}{|c} 
Dióxido de ślice $(64,2 \%)$ \\
Óxido bórico $(2,8 \%)$ \\
Óxido potásico $(8,2 \%)$ \\
Óxido sódico $(1,9 \%)$ \\
Óxido de aluminio $(19 \%)$ \\
Óxido de litio $(2,1 \%)$ \\
Óxido de litio $(2,1 \%)$ \\
Óxido de Mg $(0,5 \%)$ \\
Pentóxido de fósforo $(0,7 \%)$
\end{tabular} \\
\hline Baja fusión & $850-1100^{\circ} \mathrm{C}$ & $\begin{array}{l}\text { Recubrimiento } \\
\text { estético } \\
\text { de núcleos } \\
\text { aluminosos } \\
\text { y técnicas } \\
\text { ceramometálicas } \\
\end{array}$ & & & \begin{tabular}{|c|} 
Dióxido de silice $(69,4 \%)$ \\
Óxido bórico $(7,5 \%)$ \\
Óxido calcico $(1,9 \%)$ \\
Óxido potásico $(8,3 \%)$ \\
Óxido sódico $(4,8 \%)$ \\
Oxido de aluminio $(8,1 \%)$ \\
\end{tabular} \\
\hline $\begin{array}{l}\text { Muy baja o } \\
\text { ultrabaja fusión }\end{array}$ & $<850^{\circ} \mathrm{C}$ & $\begin{array}{c}\text { Combinación con } \\
\text { metales como el } \\
\text { titanio. Pequeñas } \\
\text { rectificaciones: } \\
\text { puntos de } \\
\text { contacto, anatomía } \\
\text { oclusal, ángulos, et } \\
\end{array}$ & $\begin{array}{l}\text { Mejora las } \\
\text { propiedades } \\
\text { de las cerámi- } \\
\text { cas de media } \\
\text { y baja fusión }\end{array}$ & & \\
\hline $\begin{array}{l}\text { Temperatura } \\
\text { ambiente }\end{array}$ & & $\begin{array}{l}\text { Procesamiento } \\
\text { directo en clínica } \\
\text { evitando el labora- } \\
\text { torio de prótesis. }\end{array}$ & $\begin{array}{c}\text { Evita } \\
\text { el laboratorio } \\
\text { de prótesis }\end{array}$ & $\begin{array}{c}\text { No se conocen } \\
\text { datos a } \\
\text { medio plazo }\end{array}$ & \\
\hline
\end{tabular}

se ha ampliado la clasificación con otras porcelanas que se trabajan a temperaturas muy inferiores e incluso en frío ${ }^{8,9}$.

En la tabla 1 resumimos las temperaturas de procesado y las principales indicaciones clínicas de este tipo de porcelanas. El lograr porcelanas con temperatura de cocción alta o baja o muy baja presenta una serie de ventajas e inconvenientes ${ }^{13}$ que se reflejan en la misma tabla.
Hemos de destacar que la principal ventaja sobre el producto final que presentan las porcelanas de medio o bajo punto de fusión es que durante el enfriamiento acontecen menores cambios dimensionales lo que se traduce en menor aparición de grietas y porosidad superficial, así como la posibilidad de que se puedan utilizar en técnicas ceramometálicas con metales con menor temperatura como el titanio y que no son objeto de análisis es este artículo. Sin embargo, la deformación que sufren por cocciones repetitivas por ejemplo por causa de pruebas o reparaciones es un factor limitante en su uso. No obstante hoy por hoy las porcelanas de bajo punto de fusión son casi tan resistentes como las de alto punto de fusión y presentan una solubilidad y translucidez adecuadas ${ }^{13}$.

Las cerámicas a temperatura ambiente se denominan así porque per- 


\begin{tabular}{|c|c|c|c|}
\hline Clasificación & Denominación & $\begin{array}{l}\text { Compuesto } \\
\text { principal }\end{array}$ & Peculiaridades \\
\hline $\begin{array}{l}\text { Cerámicas } \\
\text { convencionales }\end{array}$ & $\begin{array}{l}\text { feldespáticas } \\
\text { aluminosas }\end{array}$ & $\begin{array}{l}\text { feldespato } \\
\text { Óxido de } \\
\text { aluminio }\end{array}$ & $\begin{array}{l}\text { Poco estéticas } \\
\text { Más resistentes y } \\
\text { más estéticas que } \\
\text { feldespáticas }\end{array}$ \\
\hline $\begin{array}{l}\text { Modernas } \\
\text { vitrocerámicas }\end{array}$ & $\begin{array}{l}\text { Cerestore* } \\
\text { Dicor } \\
\text { Hi-ceram* } \\
\text { In-ceram } \\
\text { IPS-Empress } \\
\text { Optec.HSP } \\
\text { Procera/allceram } \\
\text { Cerapearl }\end{array}$ & $\begin{array}{l}\text { Alúmina } \\
\text { Vidrio de bario } \\
\text { Ślice }>50 \% \\
\text { Alúmina } \\
\text { leucita } \\
\text { Alúmina } 67 \% \\
\text { Ślice } 20 \% \\
\text { Alúmina } 85 \% \\
\text { zirconio } \\
\text { Leucita } \\
\text { Alúmina } 17 \% \\
\text { Leucita } \\
\text { Sílice }>20 \% \\
\text { Alúmina } 99,9 \% \\
\text { Sílice } \\
\text { Anhídrido } \\
\text { fosfórico }\end{array}$ & $\begin{array}{l}\text { Granos de muy } \\
\text { distintos tamaños, } \\
\text { métodos de } \\
\text { procesamiento muy } \\
\text { diversos, mejoría de } \\
\text { la resistencia } \\
\text { a la flexión }\end{array}$ \\
\hline
\end{tabular}

miten trabajar en clínica directamente sin necesidad del concurso del laboratorio dental. Aunque hay poca documentación sobre ellas se trata más de una tendencia en alza que de una realidad cotidiana.

\section{Según la composición y caracte- rísticas estructurales}

Pese a tener una composición genérica que se analizará más adelante, el predominio de uno u otro de sus componentes da lugar a un sistema de clasificación que resumimos en la tabla 2.

\section{Según el sistema de procesado y presentación}

Dado la gran cantidad de clasificaciones de las porcelanas se ha intentado un nuevo sistema de clasificación atendiendo al sistema de procesado $^{1}$ y obtención que concretamos en la tabla 3.

4. Según un criterio loco-regional de aplicación de la porcelana y con tan sólo finalidad indicativa, pues es

\begin{tabular}{|c|c|c|c|c|c|}
\hline $\begin{array}{l}\text { Clasificación } \\
\text { por el sistema } \\
\text { de procesado }\end{array}$ & $\begin{array}{l}\text { Nombre } \\
\text { comercial }\end{array}$ & Presentación & Técnica & de colores & $\begin{array}{l}\text { Recubierta superficial } \\
\text { mediante } \\
\text { otras porcelanas }\end{array}$ \\
\hline Convencional & $\begin{array}{l}\text { Optec } \\
\text { Duceram }\end{array}$ & Polvo+lechada & $\begin{array}{l}\text { Capas sobre } \\
\text { troquel }\end{array}$ & diversos & No precisa \\
\hline Colada & Dicor & $\begin{array}{l}\text { Pastillas: } \\
\text { lingotes sólidos }\end{array}$ & Cera perdida & único & Porcelana feldespática \\
\hline Torneada & $\begin{array}{l}\text { Cerec } \\
\text { Dicor MGC } \\
\text { Celay } \\
\text { Procera Allceam }\end{array}$ & $\begin{array}{l}\text { Lingotes } \\
\text { cerámicos }\end{array}$ & CAD-CAM & diversos & Porcelanas compatibles \\
\hline $\begin{array}{l}\text { Prensada o } \\
\text { inyectada }\end{array}$ & $\begin{array}{l}\text { IPS- Empress } \\
\text { Optec prensada }\end{array}$ & Lingotes cerámicos & Cera perdida & & Porcelana feldespática \\
\hline Infiltrada & In Ceram & $\begin{array}{l}\text { Polvo: Sustrato } \\
\text { poroso y vidrio } \\
\text { infiltrado }\end{array}$ & & & Porcelana feldespática \\
\hline
\end{tabular}


un mismo tipo de porcelana con pequeñas diferencias, tenemos las denominadas:

- porcelanas para dentina: también denominadas de cuerpo y cervicales, forman la parte principal del diente y de la zona cervical;

- porcelanas para esmalte: imitan el esmalte y son altamente translúcidas

- porcelanas incisales;

- porcelanas opacas: destinadas para enmascarar coloraciones subyacentes sobre las que asientan;

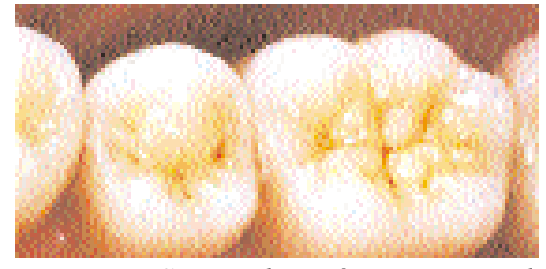

Figura 4. Corona de cerámica sin metal del 46. La proporción equilibrada de componentes en la masa cerámica permite el modelado de la misma sin menoscabo de otras propiedades físicomecánicas.

- porcelanas correctoras: se utilizan para zonas de contacto o después de corregir pequeños defectos tras

\begin{tabular}{|l|c|c|c|}
\hline \multicolumn{3}{|c|}{ Tabla 4: compuestos genéricos de las porcelanas dentales de } \\
concepción clásica o convencionales, proporción en el total de la \\
masa y funciones principales de cada uno de los compuestos
\end{tabular}

el ajuste oclusal y morfológico en clínica;

- porcelanas para glaseado: porcelanas muy transparentes que sirven para tapar los poros y grietas superficiales gracias a su capacidad para fluir a bajas temperaturas de fusión.

- Porcelana de maquillaje.

Las diferencias entre todas ellas estriba más bien en variaciones de color, translucidez, opacidad y temperatura de fusión que en diferencias en su composición.

\section{Composición de las por- celanas dentales. Venta- jas e incovenientes $y$ algunas propiedades}

No es nuestro objetivo hacer una presentación ordenada y clara de los distintos componentes que constituyen las cerámicas dentales pues es una tarea casi imposible de lograr por la gran cantidad y variedad de compuestos de que constan actualmente y por la reticencia y secretismo que manifiestan los fabricantes para desvelar los compuestos que las integran; además, conocer aisladamente la composición no tiene gran relevancia si no se sabe exactamente la técnica y la cocción.

\section{Composición básica}

Todas las porcelanas, sean del tipo que sean, están formadas por tres materias primas fundamentales cuya 
proporción varía en función de las propiedades que se quieren obtener 0 modificar y son feldespato, cuarzo (sílice) y caolín o arcilla blanca ${ }^{10,11,13}$.

El componente mayoritario es el feldespato seguido del cuarzo (forma cristalina del sílice) y en menor medida del caolín ${ }^{13}$. La diferencia entre las porcelanas dentales y las no dentales la marcó inicialmente el contenido en caolín $^{11}$ (> 50\% de la masa total en la cerámicas no dentales) responsable último de la manipulación y moldeado de la masa a la que le confiere una gran opacidad y pérdida de transparencia cuando es mayor del $10 \%$ de la masa, motivo éste por el que se redujo progresivamente su presencia hasta niveles mínimos en las porcelanas dentales actuales (fig. 4).

Además de los componentes básicos, otros materiales que se recogen en la tabla 4, aunque en menor proporción, contribuyen a la mejora del aspecto y a brindar propiedades ópticas de fluorescencia ${ }^{15,16}$.

Conocidos los principales componentes, la composición más pormenorizada según el componente mayoritario es el que sigue.

\section{Porcelanas de concep-} ción clásica, tradicional o convencionales

\section{Porcelanas feldespáticas}

Antes de iniciar la descripción de los compuestos que integran las porcelanas dentales, es conveniente hablar, aunque someramente, de la estructura que las constituyen. En cuanto a su estructura, el material cerámico puede ser considerado un material compuesto, dada la diversidad de elementos que la integran, donde la estructura predominante la constituye la matriz amorfa o vítrea mientras que otros compuestos aparecen dispersos en el seno de ellos como estructura cristalina o cristales.

Los átomos o moléculas de los materiales pueden distribuirse en el espacio de manera que se encuentren ubicados a igual distancia con los vecinos, con una distribución completamente regular, ordenada, geométrica y repetitiva. Se constituye así la estructura cristalina. Esta situación estructural es la que se encuentra fundamentalmente en los metales. En los materiales cerámicos puede darse una situación equivalente pero con más de un tipo de reticulado espacial; sin embargo también es posible que en alguno de ellos los átomos no se encuentren ordenados en un retículo cristalino geométrico y repetitivo sino ubicados casi aleatoriamente en el espacio formando una estructura amorfa o vítrea, es decir sin ningún orden geométrico repetitivo, constante o concreto ${ }^{11}$. La estructura cristalina es por tanto opuesta a la estructura amorfa o vítrea.

Las porcelanas dentales presentan una dualidad estructural. El feldespato, uno de los componentes mayoritarios de las porcelanas, una vez fundido con los óxidos metálicos solidifica en forma vítrea o amorfa y constituyen la fase vitrificada y son por tanto vidrios desde el punto de vista estructural, mientras que el cuarzo, el segundo componente cuantitativamente importante, contribuye a formar la fase cristalina de las cerámicas. En general las porcelanas feldespáti- cas responden a la composición básica mencionada anteriormente.

El feldespato es el compuesto principal, responsable de la formación de la matriz vítrea formado por silicatos de aluminio combinados con metales. En sus valencias libres se combina con $\mathrm{Na}$, K y Ca que a su vez actúan como fundentes para ayudar a la formación de la fase vítrea. El feldespato no existe puro como tal en la naturaleza sino que se presenta como feldespato potásico o sódico. La función de cada uno de ellos ya ha sido mencionada en la tabla 4. Dentro del amplio grupo de los feldespatos hay un grupo que presenta menor proporción de sílice, como la leucita (silicato de aluminio y potasio) que aparece a ciertas temperaturas durante la fusión de los feldespatos y no suele aparecer como tal mineral en la naturaleza. La presencia de leucita es uno de los sistema de incremento de la resistencia de las coronas de cerámica sin metal ${ }^{17}$. Las porcelanas que contienen mucha leucita son unas dos veces más resistentes que las que contienen cantidades menores ${ }^{13}$.

El cuarzo es el mineral más difundido de la corteza terrestre y por tanto muy abundante en la naturaleza es transparente, incoloro, brillante y muy duro. Tiene un elevado punto de fusión, un coeficiente de dilatación lineal muy pequeño y es muy estable químicamente pues apenas es atacado por los ácidos salvo el fluorhídrico. Sirve de estructura sobre la que los otros compuestos pueden acoplarse dando como resultado de la unión un material más resistente. La presencia de alúmina (óxido de aluminio) en distintas proporciones da lugar a un aumento de la dureza y disminuye de 
forma importante el coeficiente de expansión térmica de la porcelana. Su forma natural de presentación es el corindón.

El caolín es el silicato hidratado de alúmina. Es la más fina de las arcillas y su presencia es necesaria para el moldeamiento de la porcelana. Le confiere plasticidad y facilita la mezcla con el agua manteniendo la forma durante el secado y el horneado, lo que permite, dependiendo de la composición, hacerse densa y resistente sin perder la forma. El mayor problema que presenta es la pérdida de transparencia y el aspecto opaco lo que ha conducido a una disminución progresiva de la proporción en la mezcla o a la sustitución por distintas sustancias fundentes. La técnica dental a diferencia de otros usos de la porcelana, maneja en general formas pequeñas y simples por lo que la reducción del caolín en el total de la masa no altera de forma importante la manejabilidad o plasticidad de la masa y contribuye a mejorar la translucidez y la opacidad que es inherente a la presencia de caolín en las masas cerámicas.

Los distintos colores que puede adquirir la porcelana dependen de la presencia de óxidos metálicos y de su concentración de tal forma que con un mismo óxido se pueden obtener distintas gamas de un color variando las proporciones del compuesto y la temperatura de cocción.

En la actualidad no se realizan coronas feldespáticas como tales sino que los usos actuales son como recubrimiento de otras porcelanas, generalmente con elevado contenido en alúmina o vitrocerámicas, en un intento de combinar las mejores propiedades de resistencia con la carac- terización estética que las porcelanas feldespáticas pueden aportar. Marcas comerciales de cerámicas feldespáticas son entre otras la Optec, Mirage, Vintage, IPS Clasic, Ceramco, Creation/surprise, Vita Omega 900 y Vitadur Alpha 62.

\section{Porcelanas aluminosas}

En un intento de mejorar algunos de los más graves problemas que presentaban las porcelanas feldespáticas como su fragilidad, McLean y Hugues ${ }^{1}$ modificaron las porcelanas anteriores añadiendo un 50\%en volumen de alúmina (óxido de aluminio) fusionado en una matriz de vidrio de baja fusión, lo que constituía hasta ese momento el sistema reforzador más eficaz, tanto más cuanto mayor era la cantidad de alúmina incorporada. Los investigadores mencionados anteriormente comprobaron que mejoraba significativamente la resistencia respecto a las porcelanas convencionales hasta el punto que la porcelana aluminosa es el doble de resistente que la porcelana feldespática ${ }^{1}$ y su módulo de elasticidad es $50 \%$ superior al de las porcelanas tradicionales. Se obtiene así un material compuesto, en el que el material que funde primero por tener una temperatura de fusión inferior actúa como matriz mientras que el óxido de aluminio, que tiene un elevado punto de fusión queda repartido por toda la masa del primero en forma de pequeñas partículas dispersas $^{10}$. Aunque la alúmina ya se utilizaba en las porcelanas de concepción más antigua, el cambio lo constituye no tanto la utilización del compuesto como el alto contenido que presentan éste tipo de porcelanas.

La presencia de alúmina hace que el vidrio disminuya una de sus características propias, que sea menos quebradizo y disminuye el riesgo de desvitrificación proceso que consiste en una cristalización de la cerámica lo que la vuelve frágil y opaca por perder la estructura amorfa o vítrea. Este proceso también se puede producir por un elevado número de cocciones.

Con el paso del tiempo las proporciones iniciales de alúmina han ido aumentando de tal forma que actualmente algunas de las cerámicas más recientes tienen muy elevadas proporciones de óxidos de aluminio combinadas generalmente con vidrios cuyo objetivo es constituir núcleos de gran dureza que reemplacen las estructuras metálicas de las restauraciones metalcerámica y que son recubiertas por porcelanas feldespáticas convencionales ${ }^{10}$. Sin embargo, a mayor cantidad de alúmina la estética disminuye de ahí que se utilice en proporciones más elevadas en núcleos y en mucha menor cantidad en material cerámico destinado a la dentina y el esmalte ${ }^{10}$. Si se incorpora alúmina a una porcelana feldespática por encima de un $50 \%$ se obtiene una restauración poco estética, mate y muy resistente motivo por el cual en el desarrollo progresivo del material se ha combinado con otras porcelanas que aportan mejores propiedades ópticas para las capas más superficiales de la restauración dejando éste compuesto para las capas más internas.

Actualmente los núcleos de alúmina de alta resistencia están perfectamente establecidos y ha conducido a las cerámicas aluminosas de colado fraccionado. El material se conforma en un capa sólida sobre la superficie de un molde poroso (cofia) que suc- 
ciona la fase líquida por medio de fuerzas capilares. Esta cofia de alúmina que tiene un tamaño de partícula de 0,5 a 3,5 $\mu \mathrm{m}$ es recubierto con porcelana de tipo aluminosa. Tras el modelado se infunde vidrio de baja fusión de expansión térmica similar que se mezcla y difunde a través de la alúmina porosa por acción capilar produciendo una estructura de composición vitroalúmina muy densa ${ }^{15}$.

A pesar de su mayor resistencia, uno de los mayores problemas que presentan las cerámicas aluminosas es su contracción durante el procesamiento por calor, por lo que su ajuste marginal es más deficiente comparado al que se obtiene con las coronas ceramometálicas ${ }^{1}$.

Por otro lado aunque se considera que las coronas alumínicas presentan un aspecto de mayor vitalidad, son muy sensibles a la técnica por lo cual su fractura clínica es relativamente elevada ( $2 \%$ en restauraciones anteriores y $15 \%$ en posteriores) ${ }^{2}$. Actualmente se ha mejorado estas porcelanas buscando un menor índice de fracturas.

Es de destacar que la resistencia de las coronas cerámicas no sólo es imputable a la composición del material sino que depende de otros factores tan diversos como el soporte adecuado de la preparación, el grosor y rigidez de las cofias y de la cerámica de recubrimiento, el tipo de agente cementante, las imperfecciones de la superficie que actúan como desencadenantes de estrés, las microgrietas y porosidades en superficie y que afectan a los distintos tipos de porcelanas y que no se analizaran en éste artículo por escapar a los fines del mismo.

Las primeras porcelanas aluminosas

\begin{tabular}{|c|c|c|}
\hline \multicolumn{3}{|c|}{$\begin{array}{r}\text { Tabla 5: algunas ventaias e inconvenientes de } \\
\text { convencionales y modernas }\end{array}$} \\
\hline & $\begin{array}{l}\text { PORCELANAS CONVENCIONALES } \\
\text { (FELDESPÁTICAS Y ALUMINOSAS) }\end{array}$ & $\begin{array}{l}\text { PORCELANAS MODER- } \\
\text { NAS (MTROCERÁMICAS) }\end{array}$ \\
\hline Ventajas & $\begin{array}{l}\text { Estabilidad química } \\
\text { Buenas propiedades ópticas } \\
\text { Buenas propiedades de superficie } \\
\text { Biocompatibiliad muy buena } \\
\text { Elevada resistencia mecánica } \\
\text { Coef expansión próximo al diente } \\
\text { Buen ajuste marginal } \\
\text { radioopacidad }\end{array}$ & $\begin{array}{l}\text { Escasa contracción duran- } \\
\text { te y después del procesado } \\
\text { Propiedades ópticas } \\
\text { extraordinarias } \\
\text { Muy translúcidas } \\
\text { Muy estéticas } \\
\text { Muy estéticas } \\
\text { Menor desgaste de } \\
\text { antagonistas } \\
\end{array}$ \\
\hline Incovenientes & $\begin{array}{l}\text { Porosidad } \\
\text { Fragilidad: no deformable } \\
\text { Gran contracción durante la } \\
\text { cocción y el enfriamiento } \\
\text { Desgaste de antagonistas } \\
\text { proceso de laboratorio largo } \\
\text { precisa técnicos habilidosos }\end{array}$ & fragilidad \\
\hline
\end{tabular}

comercializadas (Vitadur-N, NBK 1000 , etc.) todavía hoy, casi 40 años después, siguen teniendo indicaciones a pesar de existir en el mercado porcelanas con características superiores en

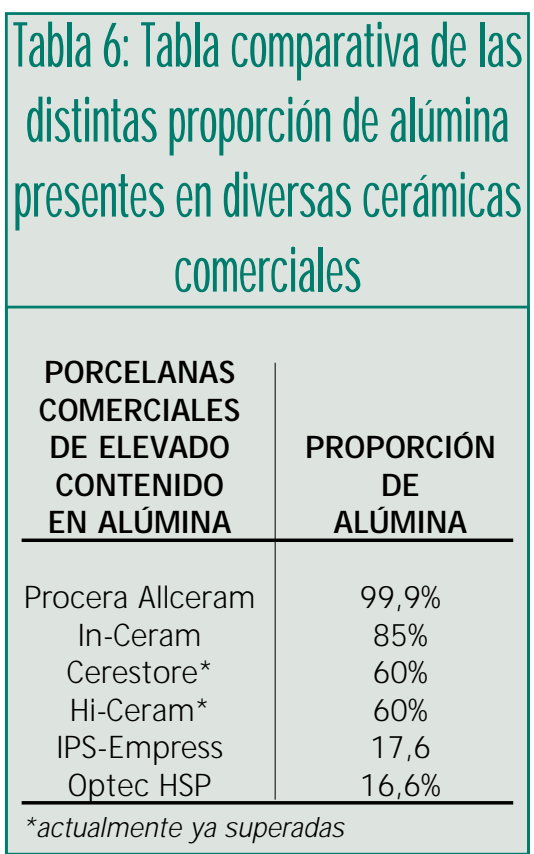

otros aspectos ${ }^{16}$. Las ventajas e inconvenientes que presentan las cerámicas de concepción clásica o convencional y las más modernas se presentan de modo resumido en la tabla 5. En la tabla 6 presentamos cerámicas con alto contenido en alúmina y la proporción de la misma en la masa cerámica.

\section{Porcelanas de concep- ción moderna, actual 0 vitrocerámicas}

El desarrollo cerámico dental es actualmente imparable; surgen nuevos materiales así como innovadores métodos de trabajar las mismas o parecidas porcelanas por lo que la composición se explica ahora no sólo 


\begin{tabular}{|c|c|c|c|c|}
\hline \multicolumn{5}{|c|}{ Tabla 7: composición de algunas vitrocerámicas } \\
\hline $\begin{array}{l}\text { Porcelana: } \\
\text { NOMBRE } \\
\text { COMERCIAL }\end{array}$ & COMPOSICIÓN & $\%$ & VENTAJAS & INCONVENIENTES \\
\hline \multirow[t]{5}{*}{ IPS Empress } & $\mathrm{SiO}_{2}$ & 63 & \multirow{5}{*}{$\begin{array}{l}\text { < cantidad de microporos } \\
\text { poca contracción: buen ajuste } \\
\text { marginal } \\
\text { manipulación relativamente } \\
\text { sencilla } \\
\text { buena transparencia } \\
\text { > resistencia a la torsión } \\
\text { que otros cerámicos }\end{array}$} & \multirow{5}{*}{$\begin{array}{l}\text { Inversión económica } \\
\text { en técnica adecuada }\end{array}$} \\
\hline & $\mathrm{Al}_{2} \mathrm{O}_{3}$ & 17,7 & & \\
\hline & $\mathrm{K}_{2} \mathrm{O}$ & 11,2 & & \\
\hline & $\mathrm{Na}_{2} \mathrm{O}$ & 4,6 & & \\
\hline & Otros: & $<1$ & & \\
\hline \multirow{5}{*}{ Dicor } & $\mathrm{SiO}_{2}$ & $55-65$ & \multirow{5}{*}{$\begin{array}{l}\text { > resistencia que las feldes- } \\
\text { páticas mejor ajuste marginal } \\
\text { que jacket convencional }\end{array}$} & \multirow{5}{*}{$\begin{array}{l}\text { Tiempo de trabajo muy largo } \\
\text { Aparatología cara } \\
\text { Pérdida maquillaje superficial } \\
\text { Discrepancia marginal } \\
\text { Cambios de color por el agente } \\
\text { cementante }\end{array}$} \\
\hline & $\mathrm{MgO}$ & $12-20$ & & \\
\hline & $\mathrm{MgF}_{2}$ & $9-13$ & & \\
\hline & $\mathrm{K}_{2} \mathrm{O}$ & $7-18$ & & \\
\hline & $\mathrm{As}_{2} \mathrm{O}_{5}$ & $0,5-8$ & & \\
\hline \multirow{6}{*}{ Cerfestore* } & $\mathrm{Al}_{2} \mathrm{O}_{3}$ & 60 & \multirow{6}{*}{$\begin{array}{l}\text { Biocompatibilidad } \\
\text { Buena adaptación marginal } \\
\text { Buena estética } \\
\text { Buena resistencia a compresion }\end{array}$} & \multirow{6}{*}{$\begin{array}{l}\text { Método de trabajo complejo } \\
\text { Coste por aparatología }\end{array}$} \\
\hline & $\mathrm{MgO}$ & 9 & & \\
\hline & Vidrio de bario & 13 & & \\
\hline & arcilla & 4 & & \\
\hline & silicona & 12 & & \\
\hline & Estearato de calcio & 1 & & \\
\hline \multirow{4}{*}{ Hi-ceram* } & $\mathrm{Al}_{2} \mathrm{O}_{3}$ & 67 & \multirow{4}{*}{$\begin{array}{l}\text { > exactitud que porcelanas } \\
\text { convencionales } \\
\text { biocompatibilidad } \\
\text { buena resistencia a la fractura }\end{array}$} & \multirow{4}{*}{$\begin{array}{l}\text { Método de trabajo complejo } \\
\text { Coste elevado } \\
\text { Cierta opacidad que precisa } \\
\text { recubrimiento convencional }\end{array}$} \\
\hline & $\mathrm{SiO}_{2}$ & 20 & & \\
\hline & $\mathrm{K}_{2} \mathrm{O}$ & 3,5 & & \\
\hline & $\mathrm{TiO}_{2}$ & 1,4 & & \\
\hline \multirow[b]{2}{*}{ In-ceram } & $\mathrm{Al}_{2} \mathrm{O}_{3}$ & 85 & \multirow{2}{*}{$\begin{array}{l}\text { Buena exactitud } \\
\text { Resistencia a la fractura }\end{array}$} & \multirow[b]{2}{*}{$\begin{array}{l}\text { Método de trabajo complejo } \\
\text { Costo elevado } \\
\text { Opacidad y color no adecuado: } \\
\text { precisa recubrimiento con } \\
\text { feldespáticas }\end{array}$} \\
\hline & $\mathrm{ZrSiO}_{4}$ & variable & & \\
\hline \multirow{4}{*}{ Optec.hsp } & $\mathrm{SiO}_{2}$ & 62,1 & \multirow[t]{4}{*}{ dureza } & \multirow{4}{*}{$\begin{array}{l}\text { Alto grado de abrasividad del } \\
\text { antagonista }\end{array}$} \\
\hline & $\mathrm{Al}_{2} \mathrm{O}_{3}$ & 16,6 & & \\
\hline & $\mathrm{K}_{2} \mathrm{O}$ & 13,5 & & \\
\hline & Otros & 10 & & \\
\hline Cerapealr & $\begin{array}{c}\text { Sílice } \\
\text { Anhídrido fosfórico } \\
\text { Oxido de mg } \\
\text { Óxido de calcio }\end{array}$ & & & \\
\hline
\end{tabular}

por los compuestos que los integran sino más bien por el método de procesado, lo que a su vez permite comprender mejor las características de los nuevos materiales utilizados. Las nuevas técnicas consisten en utilizar las distintas porcelanas aprovechando sus diferentes propiedades. En la tabla 7 se refleja la composición, con las limitaciones propias que presenta éste tipo de síntesis, de algunas cerámicas modernas.
En la actualidad hay varios sistemas de cerámica que han satisfecho las expectativas de la profesión dental ${ }^{17,18}$ recogidas en las tablas 8 y 9 donde aparecen reseñadas algunas características diferenciales entre las porcela- 


\begin{tabular}{|c|c|c|c|c|c|c|}
\hline & Tipos & Ventajas & Inconvenientes & Indicaciones & $\begin{array}{l}\text { Equipamiento } \\
\text { especial/coste }\end{array}$ & Cementación \\
\hline $\begin{array}{l}\text { Corona } \\
\text { jacket } \\
\text { aluminosa } \\
\end{array}$ & & $\begin{array}{l}\text { Estética excelente } \\
\text { barata }\end{array}$ & $\begin{array}{l}\text { Resistencia } \\
\text { moderada } \\
\text { No en fija } \\
\end{array}$ & $\begin{array}{l}\text { Buenos resultados } \\
\text { en unitarias } \\
\text { anteriores }\end{array}$ & no & $\begin{array}{l}\text { Resina/ } \\
\text { composite }\end{array}$ \\
\hline Hi Ceram & & Buena resistencia & $\begin{array}{l}\text { Brillo del núcleo } \\
\text { No en fija }\end{array}$ & & $\begin{array}{l}\text { No pero la } \\
\text { técnica requiere } \\
\text { muchos pasos }\end{array}$ & \\
\hline In Ceram & $\begin{array}{l}\text { alúmina } \\
\text { Spinell } \\
\text { zirconio }\end{array}$ & $\begin{array}{l}\text { Resistencia superior } \\
\text { Adaptación marginal } \\
\text { excelente }\end{array}$ & $\begin{array}{l}\text { Coste por } \\
\text { equipamiento } \\
\text { y tiempo de } \\
\text { fabricación }\end{array}$ & $\begin{array}{l}\text { Fija de tres } \\
\text { unidades? }\end{array}$ & $\begin{array}{l}\text { Si: coste } \\
\text { elevado }\end{array}$ & $\begin{array}{l}\text { Resina/ } \\
\text { composite }\end{array}$ \\
\hline Dicor & & $\begin{array}{l}\text { Translucidez y } \\
\text { mimetismo } \\
\text { Buena estética } \\
\text { biocompatibilidad }\end{array}$ & $\begin{array}{l}\text { Resistencia } \\
\text { moderada } \\
\text { No en fija }\end{array}$ & $\begin{array}{l}\text { Si priman los } \\
\text { requerimientos } \\
\text { estéticos }\end{array}$ & $\begin{array}{l}\text { Si: coste } \\
\text { elevado }\end{array}$ & \\
\hline Optec HSP & & $\begin{array}{l}\text { Buena estética } \\
\text { Adaptación } \\
\text { marginal buena }\end{array}$ & $\begin{array}{l}\text { Resistencia mo- } \\
\text { derada. Aplica- } \\
\text { ción limitada a } \\
\text { una prótesis } \\
\text { parcial fija }\end{array}$ & & no & $\begin{array}{l}\text { Resina/ } \\
\text { composite }\end{array}$ \\
\hline IPS Empress & $\begin{array}{l}1 \\
2\end{array}$ & $\begin{array}{l}\text { Resistencia } \\
\text { moderada } \\
\text { Excelente } \\
\text { adaptación } \\
\text { marginal } \\
\end{array}$ & $\begin{array}{l}\text { No en } \\
\text { prótesis fija }\end{array}$ & & $\begin{array}{l}\text { Si: coste } \\
\text { elevado. } \\
\text { Especial para } \\
\text { colado bajo } \\
\text { presión }\end{array}$ & $\begin{array}{l}\text { Resinas/ } \\
\text { composite }\end{array}$ \\
\hline $\begin{array}{l}\text { Alceram } \\
\text { (Cerestore) }\end{array}$ & & $\begin{array}{l}\text { Estética excelente } \\
\text { Adaptación } \\
\text { excelente } \\
\text { No contracción }\end{array}$ & $\begin{array}{l}\text { Resistencia } \\
\text { moderada }\end{array}$ & Disponibilidad? & $\begin{array}{l}\text { Si: coste } \\
\text { elevado }\end{array}$ & \\
\hline $\begin{array}{l}\text { Finesse } \\
\text { Alceram } \\
\end{array}$ & & & & & si & $\begin{array}{l}\text { Resinas/ } \\
\text { composite }\end{array}$ \\
\hline$\overline{\mathrm{OPC}}$ & & & & & si & $\begin{array}{l}\text { Resinas/ } \\
\text { composite }\end{array}$ \\
\hline Vitapress & & & & & no & $\begin{array}{l}\text { Resinas/ } \\
\text { composite }\end{array}$ \\
\hline Cerec II & & & & & $\begin{array}{l}\text { Si: coste } \\
\text { muy elevado }\end{array}$ & $\begin{array}{l}\text { Resinas/ } \\
\text { composite }\end{array}$ \\
\hline $\begin{array}{l}\text { Procera } \\
\text { Allceram } \\
\end{array}$ & & & & & $\begin{array}{l}\text { Si: coste } \\
\text { muy elevado }\end{array}$ & $\begin{array}{l}\text { Resinas/ } \\
\text { composite }\end{array}$ \\
\hline Cerapearl & & $\begin{array}{l}\text { Biocompatibilidad } \\
\text { por transformación } \\
\text { de los componentes } \\
\text { en hidroxiapatita }\end{array}$ & & & & \\
\hline
\end{tabular}

Nota: los valores de resistencia a la flexión han sido tomados de varias fuentes por lo que quizá no puedan ser comparados.

nas vitrocerámicas. Estas porcelanas se fabrican en estado vítreo, no cristalino y se convierten posteriormente al estado cristalino mediante tratamiento calórico ${ }^{15}$. Recordemos que se denomina estructura vítrea a todo fundido que solidifica en forma amor$\mathrm{fa}$, mediante redes tridimensionales cuya principal característica es la falta 


\begin{tabular}{|c|c|c|c|c|c|c|c|}
\hline \multicolumn{8}{|c|}{ Tabla 9: algunas caracteristicas de diversas porcelanas de uso más generalizadc } \\
\hline $\begin{array}{l}\text { Sistema } \\
\text { cerámico } \\
\text { marca } \\
\end{array}$ & Variaciones & Fabricante & $\begin{array}{l}\text { Resistencia } \\
\text { a flexión } \\
\text { (MPa) }\end{array}$ & $\begin{array}{l}\text { Tipo de } \\
\text { porcelana }\end{array}$ & $\begin{array}{l}\text { Método de } \\
\text { refuerzo }\end{array}$ & Mecanismo & $\begin{array}{l}\text { Forma de } \\
\text { trabajo }\end{array}$ \\
\hline $\begin{array}{l}\text { Corona jacket } \\
\text { aluminosa }\end{array}$ & & & & convencional & & Elaborada & $\begin{array}{l}\text { sobre } \\
\text { muñón }\end{array}$ \\
\hline Hi Ceram & & VIDENT & $140-141$ & $\begin{array}{l}\text { Reforzada } \\
\text { con alúmina }\end{array}$ & $\begin{array}{l}\text { Refuerzo } \\
\text { por dispersión }\end{array}$ & $\begin{array}{l}\text { Alúmina } \\
\text { sintetizada } \\
\text { en un vidrio }\end{array}$ & $\begin{array}{l}\text { Elaborada } \\
\text { sobre } \\
\text { muñón } \\
\end{array}$ \\
\hline \multirow[t]{3}{*}{ In Ceram } & alúmina & \multirow{3}{*}{\multicolumn{2}{|c|}{ VITA/VIVADENT 400-446 }} & \multirow{3}{*}{$\begin{array}{l}\text { Cofia alto } \\
\text { contenido } \\
\text { alúmina } \\
\text { prefundida } \\
\text { con vidrio }\end{array}$} & \multirow{3}{*}{$\begin{array}{l}\text { Dispersión } \\
\text { con infusión } \\
\text { vítrea }\end{array}$} & & \multirow{3}{*}{$\begin{array}{l}\text { Infiltrada/ } \\
\text { estratificada } \\
\text { Elaborada } \\
\text { sobre } \\
\text { muñón }\end{array}$} \\
\hline & spinell & & & & & & \\
\hline & zirconia & & & & & & \\
\hline Dicor & & DENTSPLY & 90- 124 & $\begin{array}{l}\text { Vitrocerámica } \\
\text { colable con } \\
\text { fluormica } \\
\text { tetrasilícica }\end{array}$ & $\begin{array}{l}\text { Cristalización } \\
\text { de vídrios }\end{array}$ & $\begin{array}{l}\text { Conversión } \\
\text { por } \\
\text { ceramización }\end{array}$ & $\begin{array}{l}\text { Técnica } \\
\text { colada o } \\
\text { inyección }\end{array}$ \\
\hline Optec HSP & & & $105-120$ & $\begin{array}{l}\text { Reforzada } \\
\text { con leucita }\end{array}$ & $\begin{array}{l}\text { Refuerzo } \\
\text { por dispersión }\end{array}$ & $\begin{array}{l}\text { Leucita } \\
\text { dispersa en } \\
\text { la corona }\end{array}$ & $\begin{array}{l}\text { Estratificada } \\
\text { Elaborada } \\
\text { sobre } \\
\text { muñón }\end{array}$ \\
\hline \multirow[t]{2}{*}{ IPS- Empress } & 1 & \multirow[t]{2}{*}{ IVOCLAR } & \multirow[t]{2}{*}{$160-180$} & \multirow[t]{2}{*}{$\begin{array}{l}\text { Reforzada } \\
\text { con leucita y } \\
\text { presionada } \\
\text { con calor }\end{array}$} & & & $\begin{array}{l}\text { Prensada/ } \\
\text { pintada } \\
\text { Prensada/ } \\
\text { estratificada }\end{array}$ \\
\hline & 2 & & & & & & $\begin{array}{l}\text { Prensada/ } \\
\text { estratificada } \\
\text { Técnica } \\
\text { colado } \\
\text { o inyección } \\
\end{array}$ \\
\hline $\begin{array}{l}\text { Alceram } \\
\text { (Cerestore) }\end{array}$ & & INNOTEK & $105-114$ & $\begin{array}{l}\text { Cerámica- } \\
\text { alúmina }\end{array}$ & $\begin{array}{l}\text { Refuerzo por } \\
\text { dispersión }\end{array}$ & $\begin{array}{l}\text { Oxido de } \\
\text { aluminio } \\
\text { magnésico } \\
\text { cristalizado } \\
\end{array}$ & $\begin{array}{l}\text { Técnica } \\
\text { colado o } \\
\text { inyección }\end{array}$ \\
\hline $\begin{array}{l}\text { Finesse } \\
\text { All-Ceram } \\
\end{array}$ & & $\begin{array}{l}\text { DENTSPLY/ } \\
\text { CERAMCO }\end{array}$ & & & & & $\begin{array}{l}\text { Prensada/ } \\
\text { estratificada }\end{array}$ \\
\hline $\mathrm{OPC}$ & & $\begin{array}{l}\text { JENERICI } \\
\text { PENTRON }\end{array}$ & & 165 & & & $\begin{array}{l}\text { Prensada/ } \\
\text { pintada } \\
\text { Prensada/ } \\
\text { estratificada }\end{array}$ \\
\hline Vitapress & & VITA & & & & & $\begin{array}{l}\text { Aplicado/ } \\
\text { prensado } \\
\end{array}$ \\
\hline Cerec II & & SIEMENS & & & & & CAD-CAM \\
\hline $\begin{array}{l}\text { Procera } \\
\text { Allceam } \\
\end{array}$ & & $\begin{array}{l}\text { NOBEL } \\
\text { BIOCARE }\end{array}$ & $420-520$ & & & & CAD-CAM \\
\hline Cerapearl & & KYOCERA & & $\begin{array}{l}\text { Apatita } \\
\text { colable }\end{array}$ & $\begin{array}{l}\text { Cristalización } \\
\text { de vidrios }\end{array}$ & $\begin{array}{l}\text { Conversión } \\
\text { por } \\
\text { cristalización } \\
\end{array}$ & $\begin{array}{l}\text { Técnica } \\
\text { colado o } \\
\text { inyección } \\
\end{array}$ \\
\hline
\end{tabular}

Nota: los valores de resistencia a la flexión han sido tomados de varias fuentes por lo que quizá no puedan ser comparados.

RCOE, 2003, Vol 8, №5, 525-546 

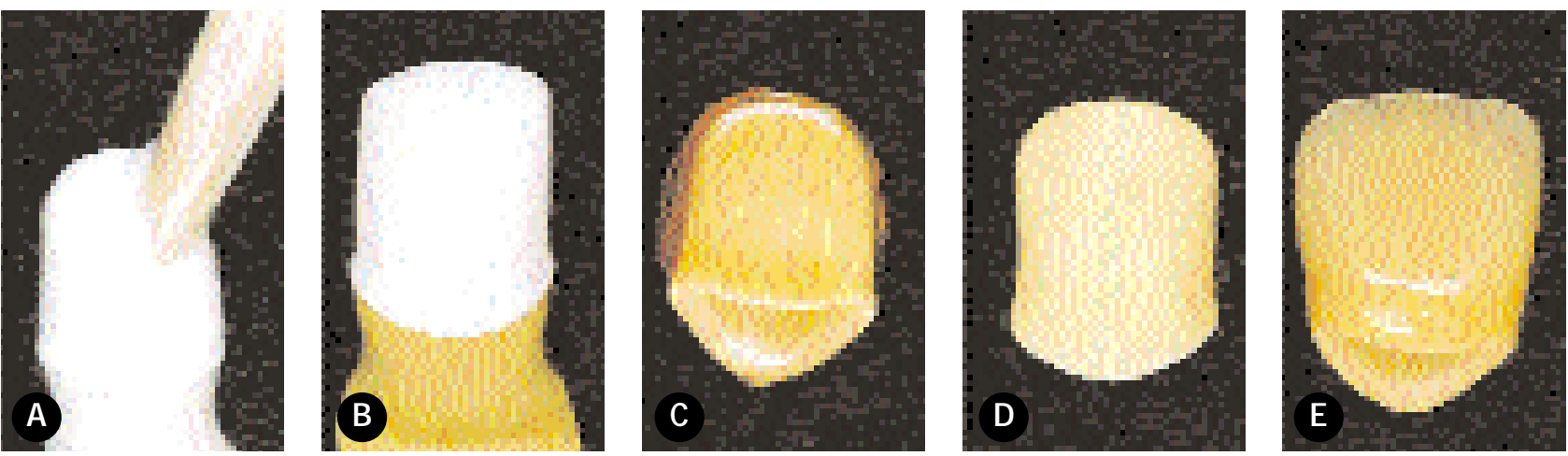

Figura 5. Secuencia de realización paso a paso de una corona vitrocerámica infiltrada con vidrio. al.Aplicación del óxido de aluminio; b/.Aspecto de la cofia sinterizada; c/. Colocación del infiltrado del vidrio; d/.Aspecto de la cofia una vez infiltrada; el.

Corona finalizada revestida mediante cerámica convencional.

total de simetría y donde ninguna unidad estructural se repite con intervalos regulares ni periódicos, es decir, sin seguir un patrón cristalino. Se denominan vitrocerámicas porque su dureza y rigidez es similar al vidrio (fig. 5). Su variedad es enorme y su composición muy heterogénea con mezclas muy complejas de diversos materiales pero todas o casi todas presentan en distintas proporciones sílice, alúmina, y partículas cristalizadas. El mayor problema que presentan es la necesidad de coloración externa que no es tan natural ni tan duradera como la porcelana convencional con pigmentos dispersos en el seno del material ${ }^{13}$. Tanto es así que para obtener la coloración definitiva es necesario aplicar vidrio coloreado sobre su superficie.

Aunque las características y las composiciones de algunas vitrocerámicas han sido reflejadas en las tablas 7 al 9, no nos es posible evaluar las mismas propiedades en todas las cerámicas revisadas pues los estudios consultados no valoran exactamente los mismos parámetros ${ }^{15,16}$.

La técnica de elaboración tan sólo se menciona pues no es objeto del presente artículo. Haremos mención a algunos aspectos puntuales dignos de destacar de las distintas porcelanas modernas que nos parecen que presentan algún interés clínico. Ante la imposibilidad de identificar las distintas vitrocerámicas por el componente mayoritario que las integra hemos optado por utilizar nombres comerciales para una mejor caracterización.

El material vitrocerámico se puede obtener por distintos métodos de procesado, se puede fundir, colar, infiltrar y tornear y según el método o forma de trabajarlo surgen nuevas clasificaciones del material más reciente o actual. Haremos un somero recorrido por algunos de ellos haciendo mención al nombre comercial de la genérica del grupo para facilitar la lectura.

\section{Vitrocerámicas coladas: como la DICOR® y CERAPEARL®}

En las vitrocerámicas coladas, el proceso de colado es similar al que se realiza para colar metales por el método de la cera perdida.

En concreto la cerámica Dicor ${ }^{\circledR}$ es una vitrocerámica colable con cristales de fluormica tretrasilícica y conversión por ceramización ${ }^{19 * *}$.
Esta cerámica se presenta como lingotes de vidrio con óxidos de aluminio y zirconio en proporciones variables que producen el bloqueo de los cristales de mica lo que aportan al material una resistencia transversal doble a la de la porcelana convencional con propiedades de comportamiento radiográfico y módulo elástico parecido al del esmalte ${ }^{15}$.

En las cerámicas coladas Dicor ${ }^{\circledR}$ la translucidez es máxima al carecer de coloración interna por lo que su efecto de mimetismo es importante aunque tiende ligeramente al gris por la formación de cristales de mica durante el proceso térmico; el efecto estético se controla y es sustancialmente mejor y más fácil de caracterizar cuando se fabrica sobre un núcleo aluminoso semiopaco y luego se recubre con cerámicas de alto contenido en leucita como la Optec ${ }^{\circledR}$ o la IPSEmpress ${ }^{\circledR}{ }^{17}$; sin embargo la diferencia de difusión térmica o incompatibilidad del vidrio con porcelanas feldespáticas aumenta la posibilidad de fracturas $^{16}$. Por otro lado la contracción, durante el proceso, es importante, en torno al $16 \%$ lo que repercute en el ajuste marginal. 
La Cerapearl@ es una vitrocerámica de apatita colable que presenta una elevada resistencia pero ningún color inherente, que debe ser aplicado posteriormente ${ }^{16}$. En su composición el óxido de calcio ocupa un alto porcentaje así como el sílice, el anhídrido fosfórico y el óxido de magnesio. La formación du-rante el procesamiento de oxiapatita que posteriormente se transforma en hidroxiapatita, ha sido implicado como uno de los motivos que la hace ser más biocompatible que otras, por su similitud con los tejidos duros del diente.

\section{Vitrocerámicas inyectadas o} prensadas: como CERESTORE ${ }^{\circledR}$, IPS EMPRESS ${ }^{\circledR}$, OPTEC PRENSADA $®, C E-$ RAPEARL $®$ colada son las de mayor contenido en leucita, especialmente la Optec $\AA$ y la IPS-Empress $₫$ y su presentación suele ser en lingotes de vidrio que se ablandan con calor y se inyecta la masa en un molde a partir de un patrón previo. Es coloreada posteriormente o bien se recubren con otra porcelana por sinterizado ${ }^{11}$ (fig. 6). Las propiedades físicomecánicas de las porcelanas inyectadas son buenas, con resistencia a la flexión variable entre $180-200 \mathrm{MPa}$, el doble que las feldespáticas convencionales y resistencia a la abrasión similar o algo mayor que el diente natura ${ }^{13}$. No presentan contracción durante el proceso bajo presión lo que le permite múltiples cocciones y su estética es superior que la aportada por las porcelana aluminosas y similar a la conseguida con cerámica infiltrada con vidrio. Además son muy resistentes a la acción de disolventes (sólo tiene acción sobre ellas el ácido fluorhídrico) y la cocción al vacío mejora la

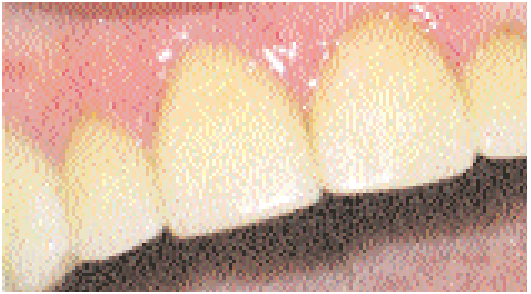

Figura 6. Coronas unitarias en los incisivos superiores realizadas mediante cerámica vitrea reforzada con leucita (IPS-Empress $\left.{ }^{\circledR}\right)$.

\section{Vitrocerámica infiltrada con vidrio: como la IN CERAM ${ }^{\circledR}$}

Son las de mayor contenido de alúmina ( $85 \%$ y por tanto las de más elevada resistencia flexural (500-630 $\mathrm{MPa})^{11,15}$ por lo que se pueden indicar no sólo para coronas unitarias sino también para puentes anteriores de pequeño tamaño ${ }^{13}$, si bien no hay estudios de los resultados a largo plazo.

En esta cerámica en el polvo sinte-
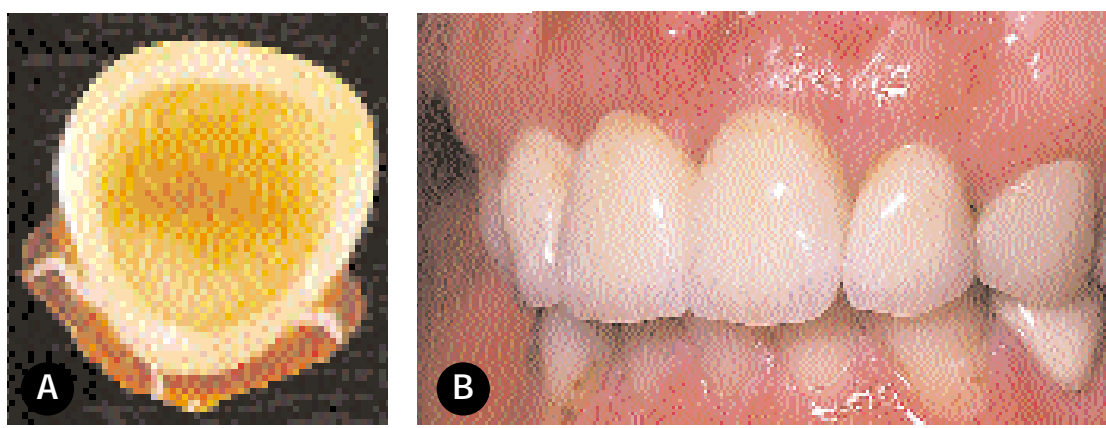

Figura 7. Coronas vitrocerámicas infiltradas con vidrio (In-ceram $\AA)$ ). a/. Aspecto que presenta el proceso de infiltración de vidrio en el núcleo sinterizado de alúmina; b/.

Corona In-Ceram ${ }^{\circledR}$ en diente 22.

resistencia a la fractura pero no evita la rotura ante impactos ${ }^{13}$. En concreto la cerámica IPS-Empress ${ }^{\circledR}$ es una cerámica vítrea reforzada con leucita que se prensa a alta temperatura en el interior de un revestimiento con base de fosfato. Esta porcelana el desarrollo del tipo 2 con un composición química a base de bisilicato de litio en elevada proporción (60\%en volumen) y ortofosfasto de litio en menor proporción, le confiere distinta microestructura que la IPS-Empress $\AA$ convencional y le proporciona ventajas como un aumento de resistencia a la flexión $(350 \pm 50 \mathrm{MPa})^{15}$. Ello ha conducido a un aumento de las indicaciones para puentes de hasta tres unidades, si bien esta indicación debe tomarse con enorme cautela. rizado de alúmina, se infiltra vidrio entre las partículas de alúmina lo que proporciona una estructura sumamente resistente debido en parte a que los cristales de óxido de aluminio muy condensados limitan la propagación de fisuras y a que la infiltración de vidrio elimina la porosidad residual ${ }^{6}$ (fig. 7). Precisa una técnica muy elaborada y debido a su elevado contenido en alúmina (75-85\% para InCeram ${ }^{\circledR}$ frente al $50 \%$ para las porcelanas aluminosas) es muy opaca, por lo que debe ser recubierta con porcelana por sinterizado para obtener las características ópticas.

De la In-Ceram ${ }^{\circledR}$ se comercializan tres variedades denominadas: alúmina, espinel de óxidos de aluminio y magnesio, y zirconio. 

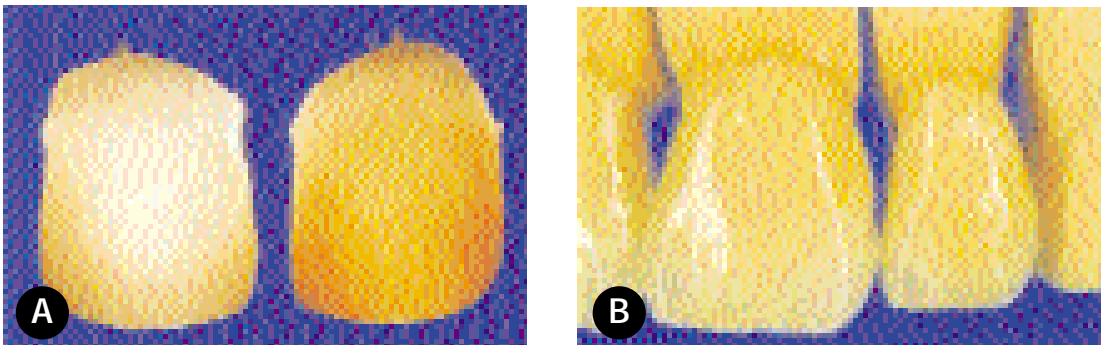

Figura 8. Vitrocerámica infiltrada con vidrio (In-Ceram $\left.{ }^{\circledR}\right)$.a/. Translucidez de un núcleo de In-ceram espinel ${ }^{\circledR}$ respecto a In-ceram alúmina ${ }^{\circledR}$. Obsérvese la mayor transparencia de In-Ceram espinel ${ }^{\circledR}$ (izquierda) que In-ceram alúmina ${ }^{\circledR}$ (derecha).b/. Aspecto de las coronas de espinel una vez finalizadas donde se aprecia su elevado aspecto estético.
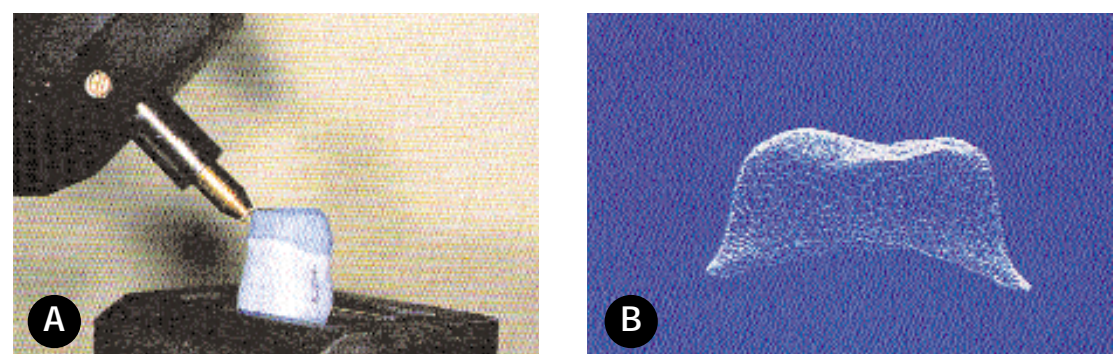

Figura 9. Sistema de diseño y fabricación asistido por ordenador. a/.Lectura óptica del muñón; b/. Información procesada tridimensionalmente a partir de la cual se produce el fresado del bloque cerámico.

- La variedad In-Ceram alúmina®, tiene gran contenido de alúmina y su contracción de sinterizado es pequeña $(0,3 \%)$ lo que unido a la escasa contracción por el tamaño de partícula da lugar a estructuras predecibles con ajuste marginal aceptable, tanto en coronas unitarias como en puentes de tres elementos ( 25 y $58 \mu$ respectivamente $)^{15}$, siendo ésta una de sus principales ventajas.

- In-Ceram espinel ${ }^{\circledR}$, utiliza una mezcla de óxido de aluminio y magnesio cristalizado y tiene que ser trabajado en vacío. Las estructuras obtenidas son muy traslúcidas, (fig. 8) pero presentan una resistencia a la flexión menor ( 15 al $40 \%$ menos que las de alto contenido en alúmina), por lo que nunca deberan utilizarse en dientes posteriores.

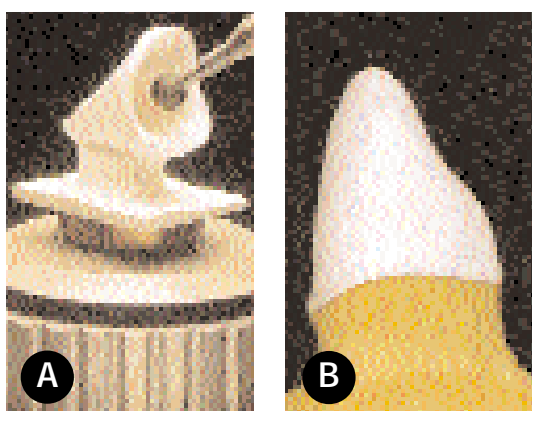

Figura 10. Sistema de diseño y fabricación asistido por ordenador. a/. Repasado del muñón obtenido a partir del bloque cerámico; b/. Cofia ajustada lista para su recubrimiento con otra porcelana de revestimiento.

- In-Ceram zirconio ${ }^{\circledR}$ está constituida por una mezcla de óxido de zirconio tetragonal (33\%) y alúmina $(67 \%)^{15}$ lo que posibilita uno de los valores más altos de tenacidad y elevación de la resistencia de flexión. Todo ello trae como consecuencia un aumento de la resistencia a la propagación de las fisuras. Los resultados son esperanzadores pero sin confirmar a largo plazo.

Investigadores como McLean consideran que los valores de resistencia alcanzados con esta cerámica constituyen un importante paso adelante en la historia de la cerámica dental, al conjugar la estética en sectores anteriores sin sacrificar la resistencia en posteriores.

\section{Vitrocerámicas talladas o tornea-} das: como los sistemas PROCERA AШCERAM ${ }^{\circledR}, \quad$ CEREC $\AA$, DICOR MGC ${ }^{\circledR}$, DURET ${ }^{\circledR}$, DENTICAID ${ }^{\circledR}, C E L A Y \circledast$, DUX®

Estos sistemas se utilizaron inicialmente para la fabricación de coronas y puentes combinadas con infraestructuras de titanio recubiertas de porcelanas de baja fusión. En la actualidad las porcelanas, bien feldespáticas o vitrocerámicas, son talladas o torneadas, sin que se astillen o fracturen sobre bloques adecuados al tamaño de la restauración, mediante un proceso de diseño asistido por ordenador (figs. 9 y 10).

Este tipo de porcelanas constan de un núcleo de alúmina de alta pureza densamente sinterizado, con un contenido de óxido de aluminio del 99,9\% lo que le confiere la mayor dureza entre los materiales cerámicos utilizados en dentistería ${ }^{20,21}$ con la posibilidad de sustituir las cofias de metal de las coronas. El mayor problema que presentan es la contracción entre el 15 y el $20 \%$ debido al alto contenido en alúmina, que se debe compensar con el aumento proporcional del tamaño del muñón ${ }^{16}$. La fabricación tiende a agrietar la cerámica lo que supone una 
debilidad considerable a nivel marginal y falta de ajuste. Otros estudios ${ }^{18}$ por el contrario ponen de manifiesto valores de ajuste marginal similares a los considerados como clínicamente aceptables.

La obtención de bloque de alúmina densamente sinterizada de alta pureza y tallada sobre muñones previamente ampliados para compensar la contracción posterior se produce por medios mecánicos altamente sofisticados y controlados por ordenador; se obtiene así una estructura cristalina con una media de tamaño del grano de $4 \mu$ y una resistencia flexural de 601 $\mathrm{Mpa}^{7}$, lo que la capacita para sustituir al metal si responde clínicamente a las buenas expectativas que apunta.

La translucidez y el color azulado que presentan las cofias de Procera y otros, debe ser complementado por los ceramistas, que generalmente recubren porcelanas de baja fusión ${ }^{15}$. El color todavía es un problema para este sistema pues la alúmina sinterizada puede variar su color dependiendo de la temperatura y es más difícil de controlar que en las porcelanas aluminosas.

Dado el auge y vertiginoso desarrollo que éstos métodos relativamente recientes están adquiriendo, diversos parámetros, como la resistencia a la flexión biaxial, a la compresión, a la tensión, efecto del grosor de la cofia, estabilidad del color con el paso del tiempo, biocompatibilidad, fracasos clínicos a los 5 y 10 años, etc., se han evaluado con resultados muy prometedores ${ }^{18}$.

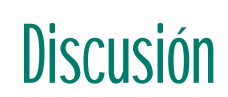

Entre los aspectos más estudiados en las coronas exclusivamente cerá- micas un gran porcentaje de los mismos se dirige al aspecto fundamental que se desea mejorar: la resistencia. Estudios realizados durante 10 años por McLean ${ }^{18}$ referidos a coronas totalmente cerámicas que inicialmente respondían a los criterios de ajuste, estética y resistencia fueron realizados para valorar si la resistencia de alguna de ellas se mostraba superior a otras. El criterio elegido fue el módulo de rotura o la resistencia a la flexión en especimenes de laboratorio en barra. Las conclusiones de este estudio pusieron de manifiesto las dificultades encontradas para evaluar la resistencia de los materiales cerámicos, y se comprobó que no era posible comparar los sistemas estudiados al existir una amplísima variación en los valores medios, obtenidos en cuanto a la resistencia a la flexión, valores que se reflejan en la tabla 9. Los valores obtenidos se dan exclusivamente con fines comparativos y no responden a las variaciones encontradas entre las muestras $^{18}$.

Por otro lado, los valores que influyen en la resistencia de los materiales cerámicos dependen de una serie de valores en cuanto a composición y estructura difíciles de controlar en los especimenes de laboratorio y que en ningún caso pueden ser extrapolados a los valores de las coronas cerámicas ya sea estudiada en el laboratorio y mucho menos en la clínica.

Es lógico pensar que si las barras de cerámica del laboratorio no pueden ser comparadas entre sí a pesar de las condiciones estándar en las que se realizan las investigaciones, mucho menos podrán ser extrapolados los valores encontrados a las coronas clínicas donde la dispersión de paráme- tros de diseño y realización son mucho mayores y más difíciles de estandarizar que las obtenidas de muestras de laboratorio.

No debemos olvidar que los factores que contribuyen a aumentar la resistencia no dependen exclusivamente de la composición de las porcelanas sino también la uniformidad de la reducción dentaria, la presencia de factores oclusales favorables 0 adversos, la situación de la restauración, la naturaleza del antagonista, el medio cementante, la técnica de laboratorio y un largo etcétera contribuyen a la supervivencia de las coronas en el medio bucal ${ }^{17}$.

Así creemos que los valores absolutos encontrados en las diversas investigaciones parecen menos importantes para la evaluación de los parámetros elegidos inicialmente que los modelos que sirven de referencia, como la corona jacket aluminosa.

El comportamiento de las coronas de los núcleos de alúmina, la vitrocerámica colada (Dicor $\left.{ }^{\circledR}\right)$ la cerámica aluminosa sin contracción (Cerestore $\left.{ }^{\circledR}\right)$, la cerámica reforzada con leucita (Optec $\left.{ }^{\circledR}\right)$ y la porcelana de núcleo aluminoso (Hi-Ceram ${ }^{\circledR}$ ) son aproximadamente iguales y relativamente comparables en resistencia cuando se valora en especimenes en barra ${ }^{17}$.

Similares resultados se citan cuando los estudios se realizan sobre muestras reales; así las de cerámica aluminosa sin contracción (Cerestore ${ }^{\circledR}$ ), vitrocerámica colada (Dicor ${ }^{\circledR}$ ) y las jacket de porcelanas aluminosas no muestran una resistencia inferior a la fractura sino que su resistencia es muy similar ${ }^{22}$.

Los resultados de estas investigaciones muestran que en el intervalo 
90-140 MPa es difícil seleccionar un sistema superior a otro, y que dado que actualmente se consiguen cerámicas con resistencia la flexión muy superiores, no se deberían utilizar de manera rutinaria cerámicas con valores de resistencia a la flexión $<150$ MPa en grupos posteriores o en prótesis parcial fija ${ }^{23}$ por el riesgo potencial de fractura que presentan. Sin embargo, estos datos no son compartidos por todos los investigadores puesto que resistencias a la flexión tan bajas como 90-140 Mpa han presentado un índice de fracaso a los 7 años del $2 \%$ que representa un índice muy bajo y aceptable clínicamente².

Atendiendo a este criterio exclusivamente las indicaciones de cerámica en grupos posteriores, sometidos, en principio a fuerzas oclusales más elevadas, deberían, según McLean y Seghi, estar limitados a las cerámicas reforzadas y presionadas por calor (IPS-Empress ${ }^{\circledR}$, valores de $160-180$ $\mathrm{MPa})^{15}$, cerámica aluminosa de colado fraccionado (In-Ceram ${ }^{\circledR}$, valores de 420-520 MPa) ${ }^{11,15}$ y coronas de alúmina de alta pureza densamente sinterizadas (Porcera Allceram $\AA$, valores variables entre 420-600 MPa) ${ }^{7}$. Estos valores de resistencia a la flexión coinciden también con el contenido en alúmina. Así la mayor resistencia debería darse y se da, en las coronas de Procera Allceram ${ }^{\circledR}$ ( $98 \%$ de alúmina) In-Ceram ${ }^{\circledR} \quad(75-85 \%)$ y Hi-Ceram ${ }^{\circledR}$ $(60 \%) 18,23$. Los valores aceptables de IPS-Empress ${ }^{\circledR}$ se deben a su refuerzo en leucita $(17,7 \%)$ y es llamativo que otra porcelana reforzada por leucita como la Optec ${ }^{\circledR}$, en la que se esperarían valores de resistencia a la flexión similares presente cifras muy inferiores (105-120 MPa). Es posible que la resistencia del material no sea debida exclusivamente a la composición sino que otros factores como la estructura o incluso la técnica puedan modificar las propiedades debidas a los componentes que las integran.

Por otro lado, las pruebas de fatiga indican que IPS-Empress es menos susceptible a la fatiga que la porcelana feldespática. Sin embargo presenta una resistencia a la compresión menor que las coronas de metalcerámica o las In-Ceram ${ }^{\circledR 24}$. Cuando se comparan los valores de resistencia a la flexión de diversos materiales cerámicos de uso actual, IPS-Empress ${ }^{\circledR}$ muestra una resistencia a la fractura menor que las cerámicas reforzadas con óxido de aluminio ${ }^{25}$ lo que contraindica su uso en prótesis parciales fijas pero posibilita su uso en coronas unitarias.

Hace unos años, en 1992, las cerámicas sin metal más utilizadas en esa fecha fueron estudiados por Pröbster $^{27}$ comparándolas con las coronas de metalcerámica. Pröbster manifiesta que las coronas de In-Ceram $\AA$ poseían mayor resistencia a la compresión que las IPS-Empress ${ }^{\circledR}$ pero ambas eran inferiores a las coronas metalcerámica. Según este autor el comportamiento de la resistencia a la flexión y la resistencia a la fractura son los parámetros más relevantes para su evaluación clínica ${ }^{27}$.

En este sentido, actualmente dentro de las distintas variedades que presenta el sistema cerámico InCeram ${ }^{\circledR}$ (alúmina, espinel de óxido de magnesio y aluminio cristalizado y zirconio) la resistencia a la flexión es significativamente superior que otros sistemas cerámicos estudiados ${ }^{26}$. Gracias a esta propiedad, ésta cerámica se puede emplear y ha sido empleada para realizar puentes de hasta tres unidades en la región anterior. Sin embargo otras porcelanas con semejante resistencia como las reforzadas con leucita (IPS-Empress $\left.{ }^{\circledR}\right)$ pueden también tener idéntica indicación aunque con reservas.

A pesar de la buenas expectativas que este material presenta estos datos o indicaciones teóricas en función de la resistencia deben confirmarse a medio-largo plazo ${ }^{26}$.

Para aumentar aún mas la confusión respecto al parámetro de resistencia algunos estudios presentan una resistencia de las coronas In-Ceram ${ }^{\circledR}$ hasta 2,5 veces más resistentes que Dicor ${ }^{\circledR}$ y más de tres que las coronas feldespáticas tradicionales. Sin embargo, como ya se ha comentado, las mejores propiedades mecánicas las presentan las coronas In-ceram ${ }^{\circledR}$ seguidas de $\mathrm{Hi}$-ceram ${ }^{\circledR}$, ya abandonada, y Dicor ${ }^{\circledR}$ si bien esta última es muy laboriosa y presenta un costo muy elevado y poco asequible por parte de la mayoría de los profesionales ${ }^{27}$.

La resistencia a la flexión biaxial de Procera Allceram ${ }^{\circledR}$ también era significativamente mayor que IPS Empress $\AA^{20}$.

En referencia a los aspectos estéticos, en general son muy buenos en casi todas las porcelanas, y superior en cuanto a transparencia en la Dicor ${ }^{\circledR}$ e In-Ceram espinel ${ }^{\circledR}$, máxime cuando se revisten con cerámicas feldespáticas. Sin embargo las porcelanas más translúcidas deben colorearse superficialmente y pueden perder con el paso del tiempo su caracterización por desgaste lo cual supone una limitación clínica importante a corto/medio plazo que no debe ser olvidada y que creemos será mejorada en un futuro próximo.

Aun cuando los sistemas de cerá- 
mica reforzada con alúmina mejoran significativamente la reflexión de la luz cuando se comparan con las coronas de metalcerámica, no hay que olvidar sin embargo que el óxido de aluminio opaco no lo hace y por tanto disminuye la translucidez, cuando se comparan con sistemas que utilizan como refuerzo los cristales de leucita (Optec ${ }^{\circledR}$, IPS-Empress $\left.{ }^{\circledR}\right)$. Así en los casos en lo que se necesite una buena transmisión y reflexión de la luz por requerimientos altamente estéticos, donde no se precise una resistencia máxima, el empleo de una espinela de óxido de magnesio y aluminio estará indicado por presentar cualidades de transiluminación similares al diente natural ${ }^{29}$ (fig. 8).

La biocompatibilidad junto con la estética es otro de los parámetros más conseguidos en estos materiales siendo muy buena en todas ellas, quizá con sobresaliente en la Cerapearl ${ }^{\circledR}$ por contener compuestos que dan lugar a oxiapatita que posteriormente se transforman en hidroxiapatita altamente biocompatibles por su analogía con los tejidos calcificados del diente ${ }^{21}$.

El buen ajuste marginal como uno de los factores que influye en la supervivencia o el éxito clínico de las coronas a largo plazo, y dependiendo de la contracción o distorsión durante el procesado. La Cerestore ${ }^{\circledR}$ era una cerámica con casi ausencia de contracción por lo que las restauraciones mediante porcelanas Cerestore ${ }^{\circledR}$ poseen ausencia de contracción por lo que su ajuste marginal es bueno y su resistencia teórica aceptable en los estudios realizados; sin embargo, prácticamente se han retirado por su elevado fracaso clínico y por el complejo y costoso proceso de elaboración.

\begin{tabular}{|c|c|}
\hline \multicolumn{2}{|c|}{$\begin{array}{l}\text { Tabla 10: abrasión del diente antagonis } \\
\text { cerámicos }\end{array}$} \\
\hline PRODUCTO & $\begin{array}{l}\text { ABRASIVDAD CONTRA DIENTES } \\
\text { NATURALES (DUREZA) }\end{array}$ \\
\hline \multicolumn{2}{|r|}{ CERÁMICA TRADICIONAL } \\
\hline optec & > que feldespática por alto contenido en leucita \\
\hline duceram & Próxima al diente natural por ausencia de leucita \\
\hline \multicolumn{2}{|r|}{ CERÁMICA COLADA } \\
\hline dicor & $\begin{array}{l}\text { La misma que el diente; es más blanda que la } \\
\text { feldespática excepto la dicor plus que es igual }\end{array}$ \\
\hline \multicolumn{2}{|r|}{ CERÁMICA TORNEADA } \\
\hline Cerec vitablocks Mark I & Similar a feldespática \\
\hline Cerec vitablocks Mark II & Similar a esmalte \\
\hline Dicor MGC & Entre cerec I y II \\
\hline Celay & Como Cerec II \\
\hline \multicolumn{2}{|r|}{ CERÁMICA INYECTADA } \\
\hline IPS Empress & $\begin{array}{l}\text { > que feldespática por el mayor contenido en } \\
\text { leucita tras el tratamiento térmico }\end{array}$ \\
\hline OPC & Igual al anterior \\
\hline \multicolumn{2}{|r|}{ CERÁMICA INFILTRADA } \\
\hline In-ceram & Igual a feldespática \\
\hline
\end{tabular}

Se podría decir que las restauraciones hechas con la porcelana InCeram ${ }^{\circledR}$ son las que mejor ajuste marginal ofrecen debido a que sufren menos distorsión durante el procesado. Esto parece una contradicción pues en su composición tienen un alto porcentaje de alúmina que a priori conlleva una mayor distorsión y que se compensa aumentando proporcionalmente el tamaño de los muñones.

En ésta línea, las coronas de más alto contenido en alúmina, inicialmente se consideraban con escaso ajuste marginal como la Procera Allceram ${ }^{\circledR}$ lo que podría constituir una limitación clínica para su aplicación. Sin embargo estudios recientes realizados por May, Razzoog y cols ${ }^{30}$ con- tradicen los hallazgos encontrados inicialmente. No obstante, el ajuste marginal no es tan bueno como el referido para In-Ceram $(25 \mu)$, pues se han dado cifras para las coronas de Procera Allceram ${ }^{\circledR}$ de $70 \mu$, valores considerados para algunos clínicos como aceptables al estar por debajo de $100 \mu^{20}$. El ajuste marginal, que en un principio se consideró una de las limitaciones de las coronas obtenidas por métodos CAD-CAM, se encuentra también dentro de los límites considerados clínicamente aceptables ${ }^{29,30}$.

El desgaste de los dientes antagonistas, también valorado como limitante en el uso clínico de restauraciones cerámicas y que alcanza sus valores máximos en las feldespáticas conven- 
cionales, es mínimo y similar al del diente natural en la cerámica de colado como la Dicor ${ }^{\circledR}$ y debería por tanto ser utilizada ésta cerámica cuando el antagonista así lo requiera ${ }^{14}$. La mayor abrasividad para el antagonista la presenta una cerámica como la Optec HSP ${ }^{\circledR}$ por su elevado contenido en leucita siendo mucho menor para la cerámica Procera Allceram $^{23}$. Este dato es altamente esperanzador para el clínico ya que un menor desgaste del esmalte siempre redunda en beneficio del paciente. En la tabla 10 se presentan los distintos grados de abrasividad para los dientes antagonistas en diversos sistemas cerámicos usados actualmente.

\section{Expectativas futuras}

El desarrollo de las restauraciones completamente cerámicas va a continuar buscando porcelanas más resistentes mediante nuevos procesos de elaboración, probablemente asistidos por ordenador y potenciado su uso por el desarrollo de nuevos y mejores sistemas de adhesión o cementado lo que facilitará su empleo en la clínica.

A la vista de los datos actuales cree- mos que el uso de cerámica dental es imparable, pero que deben seguir investigándose y mejorándose algunos aspectos que, hoy por hoy, aun no son satisfactorios y que constituyen una limitación para su uso clínico generalizado. Entre esos aspectos destacamos los siguientes:

- resistencia apropiada y menor fragilidad lo que posibilitaría puentes exclusivamente cerámicos y de mayor número de piezas, así como restauraciones en cualquier lugar de la arcada;

- menores grosores de coronas, que permitirían tallados más conservadores con la estructura dentaria;

- mínimo desgaste del antagonista o ausencia del mismo;

- disminución del costo, incluso en la tecnología asistida por ordenador;

- precisión de ajuste marginal;

- porcelanas que se puedan trabajar en frío sin el concurso del laboratorio en la propia consulta.

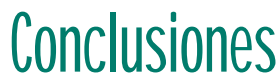

1. La elección del tipo de cerámica más conveniente dentro de los citados, depende de la situación clínica par- ticular de tal forma que los materiales cerámicos más resistentes deben colocarse donde tengan que soportar más cargas y los menos en las situaciones donde la abrasión dentaria pueda ser más conflictiva. La principal base del éxito clínico son la indicaciones correctas.

2. Al no existir estudios a largo plazo deben utilizarse de forma selectiva hasta comprobar que la supervivencia clínica se mantiene en el tiempo.

3. El éxito estético, en manos de técnicos hábiles está asegurado prácticamente con todos los sistemas estudiados.

4. El futuro será prometedor cuando la selección del paciente y el material sea la apropiada y se disponga de un buen laboratorio. La mejora de sus propiedades mecánicas (tanto en resistencia como en desgaste del antagonista), el abaratamiento de los procedimientos tecnológicos y su empleo mayoritario como material restaurador odontológico presagian un futuro esperanzador para las restauraciones cerámicas dentales libres de metal.

\section{Agradecimientos}

A la casa Vita por la cesión de las imágenes de las figuras 2, 3, 4, 5, 7a, 8 y 10 y a la casa Nobel Biocare por la cesión de la figura 9. 


\section{Bibliografía recomendada}

Para profundizar en la lectura de este tema, el/los autor/es considera/an interesantes los artículos que aparecen señalados del siguiente modo: * de interés ${ }^{* *}$ de especial interés.

1. McLean JW. The science and art of dental ceramics. Oper Dent 1991;16:149-56.

2. Rosenblum MA, Schulman A. Una revisión de las restauraciones de cerámica pura. J Am Dent Assoc (ed española) 1998;1:11-24.

3. Pröbster L. EI desarrollo de las restaturaciones completamente cerámicas. Un compendio histórico. Quintessence (ed española) 1998;11: 515-9.

4. Kelly JR, Nishimura I, Campell SD. Ceramics in dentristry: historical roots and current perspectives. J Prosthet Dent 1996;75:18-32.

5*. Sozio RB, Riley EJ. The shrink-free ceramic crown. J Prosthet Dent 1983;69:1982-5. Artículo que en su tiempo supuso un giro radi-

cal no sólo en la composición sino también en las indicaciones de las coronas cerámicas.

6. Pröbster L, Diehl J. Split-casting alumina ceramics for crown and bridges restorations. Quintessence Int 1992;23:25-31.

7**. Anderson M, Oden A. A new all ceramic crown. A dense-sintered, high-purity alumina coping with porcelain. Acta Odontol Scand 1993;51:59-64.

Artículo de gran interés pues supuso un cambio en la concepción a la hora de fabricar coronas totalmente cerámicas.

8. Sorensen JA, Kang S-K, Torres TJ, Knode H. Inceram fixed partial dentures: tree year clinical trial results. Calif Dent Assoc J 1998;26: 207-14.

9. Oden A, Arvidson K, Engquist B et al. Procera allceram bridges. Int J Prosthodont 1999;12: 452-5

10. Vega del Barrio JM, Baños Marín JL. Porcelanas y cerámicas dentales. En: Vega del Barrio JM, ed. Materiales en Odontología: fundamen- tos biológicos, clínicos, biofísicos y fisicoquímicos. Madrid: Avances Médico-Dentales 1996:439-53.

11. Macchi RL. Porcelana. En: Macchi RL, ed. Materiales dentales. $3^{\mathrm{a}}$ ed. Buenos Aires: Editorial Médica Panamericana 2000:287-97.

12. Oden A, Andersson M, Krystek-Ondracek I. Five-year evaluation of Procera AllCeram crowns. J Prosthet Dent 1998;80:450-6.

13. Craig RG. Cerámicas. En: Craig RG, ed. Materiales de Odontología restauradora, $10^{\mathrm{a}}$ ed. Madrid: Harcourt Brace España, 1998:467-84.

14. Seghi RR, Rosentiel SF, Bauer P. Abrasion of human enamel by different dental ceramics in vitro. J Dent Res 1991;70:221-5.

15. McLean JW, Jeansonne EE, Chiche G, Pinault A. Coronas totalmente cerámicas y coronas laminadas. En: Chiche G, Pinault A, ed. Prótesis fija estética en dientes anteriores. Barcelona: Masson 1998:97-113.

16. McLean JW. High strengh ceramics. Quintessence Int 1987;18:97-103

17. Rekow D. Dental CAD-CAM systems: what is the state of the art?. J Am Dent Assoc 1991; 122:42-8.

18. Andersson M, Razzoog ME, Oden A, Hegenbarth EA, Lang BR. Procera: a new way to achieve an all-ceramic crown. Quintessence Int 1998;29:285-96.

$19 * *$. McLean JW. Evolution of dental ceramics in the twentieth century. $\mathrm{J}$ Prosthet Dent 2001;85:61-6.

Revisión crítica y actualizada de las restauraciones cerámicas vistas con la perspectiva de los años y valorando aspectos importantes desde el punto de vista clínico.

20. Wagner WC, Chu TM. Biaxial flexural strengh and indentantion fracture toghness of tree new dental core ceramics. J Prosthet Dent 1996;76:140-4.

21. Zeng K, Oden A, Rowcliffe D. Flexure test on dental ceramics. Int Prosthodont Dent 1996;9: 434-9.

22. Dickinson AJG, Moore BK, Harris RK, Dykema RW. A comparative study of the strengh of aluminous porcelain and all ceramic crowns. J Prosthet Dent 1989;61: 297-302.

23. Seghi RR, Daher T, Caputo D. Relative flexural strengh of dental restorative ceramics. Dent Mater 1990;6:181-4.

24. Myers ML, Erge JW, Fairhurst CW, Ringle RD. Fatigue failure parameters of IPS-Empress porcelain. Int J Prosthodont 1994; 7:545-53.

25. Pröbster L. Compressive strengh of two modern all-ceramic crows. Int J Prosthodont 1992;5:409-14.

26. Seghi RR, Sorensen JA. Relative flexural strengh of six new ceramic materials. Int J Prosthodont 1995;8:239-46.

27. Christensen R, Christensen G. Service potential of all-ceramic fixed prostheses in areas of variying risk (abstrac 1716). J Dent Res 1992; 71:320.

28. Paul SJ, Pietrobon N, Schärer P. The new In-ceram spinell system. A case report. Int Periodont Res Dent Thecnol 1995;1 5:521-7.

29. May KB, Razzoog ME, Lang BR, Wang RF. Marginal fit: the Procera Allceram crown. J Dent Res 1997;76:311-5.

30. Hacker CH, Wagneer WC, Razzoog ME. An in vitro investigation of the wear of enamel on porcelain and gold in saliva. $J$ Prosthet Dent 1996;75:14-7. 